\title{
Human Factors for Situation Assessment in Power Grid Operations
}

\author{
RT Guttromson \\ FL Greitzer \\ ML Paget \\ A Schur
}

August 2007

\section{Pacific Northwest}




\title{
DISCLAIMER
}

This report was prepared as an account of work sponsored by an agency of the United States Government. Neither the United States Government nor any agency thereof, nor Battelle Memorial Institute, nor any of their employees, makes any warranty, express or implied, or assumes any legal liability or responsibility for the accuracy, completeness, or usefulness of any information, apparatus, product, or process disclosed, or represents that its use would not infringe privately owned rights. Reference herein to any specific commercial product, process, or service by trade name, trademark, manufacturer, or otherwise does not necessarily constitute or imply its endorsement, recommendation, or favoring by the United States Government or any agency thereof, or Battelle Memorial Institute. The views and opinions of authors expressed herein do not necessarily state or reflect those of the United States Government or any agency thereof.

\author{
PACIFIC NORTHWEST NATIONAL LABORATORY \\ operated by \\ BATTELLE \\ for the \\ UNITED STATES DEPARTMENT OF ENERGY \\ under Contract DE-AC05-76RL01830
}

Printed in the United States of America

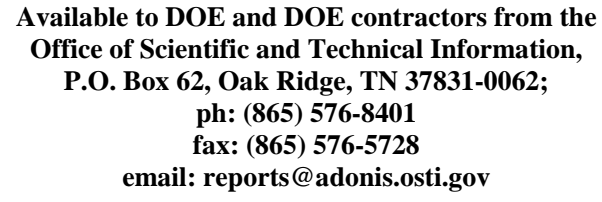

Available to the public from the National Technical Information Service, U.S. Department of Commerce, 5285 Port Royal Rd., Springfield, VA 22161 ph: (800) $553-6847$ fax: (703) 605-6900 email: orders@ntis.fedworld.gov online ordering: http://www.ntis.gov/ordering.htm 


\section{Executive Summary}

Despite advances in technology, power system operators must assimilate overwhelming amounts of data to keep the grid operating. Analyses of recent blackouts have clearly demonstrated the need to enhance the operator's situation awareness (SA). The long-term objective of this research is to integrate valuable technologies into the grid operator environment that support decision making under normal and abnormal operating conditions and remove non-technical barriers to enable the optimum use of these technologies by individuals working alone and as a team. More specifically, the research aims to identify methods and principles to increase SA of grid operators in the context of system conditions that are representative or common across operating entities and develop operationally relevant experimental methods for studying technologies and operational practices which contribute to SA.

With increasing complexity and interconnectivity of the grid, the scope and complexity of situation awareness have grown. New paradigms are needed to guide research and tool development aimed to enhance and improve operations. In reviewing related research, operating practices, systems, and tools, the present study established a taxonomy that provides a perspective on research and development surrounding power grid situation awareness and clarifies the field of human factors/SA for grid operations. Information sources that were used to identify critical factors underlying SA included interviews with experienced operational personnel, available historical summaries and transcripts of abnormal conditions and outages (e.g., the August 14, 2003 blackout), scientific literature, operational policies/procedures, and other documentation.

Our analysis of August 2003 blackout transcripts and interviews adopted a different perspective than previous analyses of this material, and we complemented this analysis with additional interviews. Based on our analysis and a broad literature review, we advocate a new perspective on SA in terms of sensemaking, also called situated or ecological decision making, where the focus of the investigation is to understand why the decision maker(s) experienced the situation the way they did, or why what they saw made sense to them at the time. This perspective is distinct from the traditional branch of human factors research in the field which focuses more on ergonomics and the transactional relationship between the human operator and the systems. Consistent with our findings from the literature review, we recognized an over-arching need to focus SA research on issues surrounding the concept of shared knowledge; e.g., awareness of what is happening in adjacent areas as well as one's own area of responsibility. Major findings were:

- Inadequate communication/information sharing is pervasive. It is clear from the 2003 Blackout report that the failure to adequately communicate and share critical status information is not an isolated problem that happened during the afternoon of the blackout, but rather that it is a pervasive problem that clearly represents a systemic and chronic issue that must be corrected.

- Information is available, but not used. Many tools and mechanisms exist for operators to build awareness of the physical grid system, yet the transcripts reveal that they still need to call and exchange information with operators of neighboring areas to improve or validate their SA. The specific types of information that they request are quite predictable and, in most cases, cover information that could be available to both operators and reliability coordinators through readily available displays or other data sources. The blackout interviews reveal a number of reasons for operators to seek corroboration or verification of information relevant to the grid status in areas. 
- Shared Knowledge is Required on Operations/Actions as Well as Physical Status. In an ideal, technologically and organizationally perfect world, every control room and every reliability coordinator may have access to complete data across all regional control areas and yet, there would still be reason for the operators to call each other to gain and improve their SA of power grid operations. Analysis of both the blackout transcripts and interviews with experts reveal the importance of exchanging information about the status of operations affecting the power gridwhat decisions are being considered, what decisions have been made and where in context of location in the grid, what actions have been taken, which actions are about to be taken and where, what options are available for maintaining stability of the interconnected grid, and what other factors need to be considered. While operators and reliability coordinators seek to improve their SA of the general status of neighboring areas, it is not just the physical status of grid components that is needed to refine that SA. Operator and reliability coordinator (RC) situation awareness of neighboring areas includes a general understanding of the status of operations in areas outside their area.

- Need to redefine "Normal Operations."Normal operations" is a fluid state of events. Combinations of parameters are constantly moving within and outside a norm of operations. Interviews and analysis of the August 14 blackout found a pattern where operators and reliability coordinators considered the movement of parameters beyond the traditional limits of normal operations as normal because the condition was categorized as a common, yet relatively serious occurrence. Traditional studies have characterized this condition as abnormal and studied as such where they are actually investigating what the operator needed (past) as a static reference. Instead, what is needed is establishing the PRESENT status in context of a dynamic or fluid point of reference.

- Situation Awareness as sensemaking and shared knowledge. The findings and perspectives presented in this report argue that a promising direction for future research on human factors/ situation awareness in power grid operations is to focus on further defining factors and user interaction/tool requirements that address issues of sensemaking and shared knowledge. This means that research is needed that transcends the more traditional human factors/visualization studies centered on transactions between the user and the computer.

To support such research, the PNNL Electricity Infrastructure Operations Center (EIOC) is uniquely positioned as a test bed for evaluating the utility and effectiveness of tools or possible interaction design and visualization solutions and to examine issues such as nontechnical barriers affecting SA and their implications for tool development. We envision both highly focused experiments investigating specific design issues (i.e., questions addressing transactional user interface design and visualization concepts) as well as broader, highlevel issues that address wide-area indicators and factors affecting SA. Possible research studies following this line of thought are briefly described.

We conclude that a promising direction for future research on human factors/situation awareness in power grid operations is to focus on further defining factors and user interaction/tool requirements that address issues of sensemaking and shared knowledge. It is not sufficient that the new information needs of the operators be examined solely from an individual viewpoint: it is critical that an understanding be gained from the perspective of a shared view, since the events that unfold and associated sensemaking requirements do not occur in vacuum but are intimately involved, temporally and spatially, with events and conditions outside of an individual's responsibility and awareness (access).

The necessary research must transcend the more traditional human factors/visualization studies centered on transactions between the user and the computer. The Electricity Infrastructure Operations Center (EIOC) at PNNL provides a necessary test environment to support empirical studies with simulated (and actual) data and experienced power grid operators. The report concludes by describing possible research studies on information interaction, communication, and visualization concepts informed by foundational SA research. 


\section{Contents}

Executive Summary ……………….............................................................................................................. iii

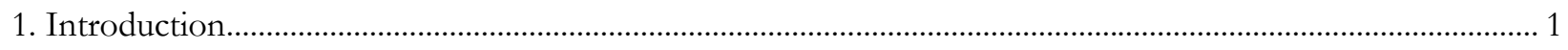

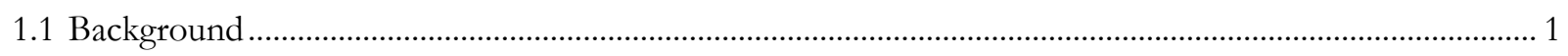

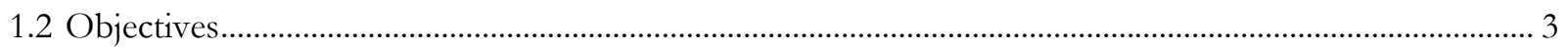

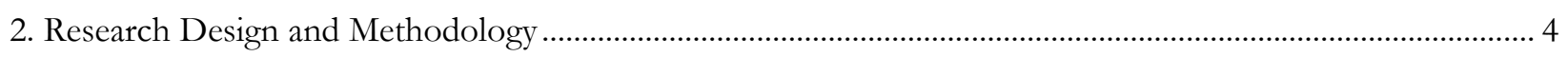

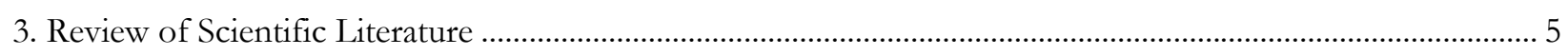

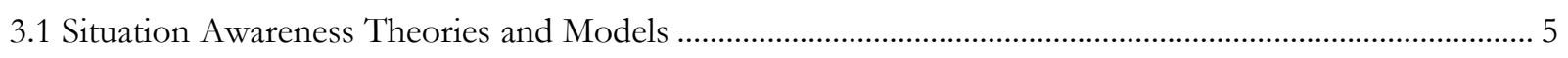

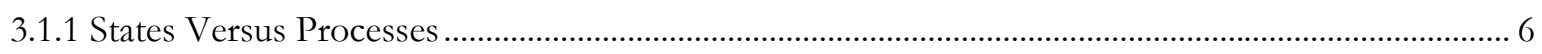

3.1.2 Operator-Focused Versus Situation Focused .................................................................................... 8

3.1.3 Implications for Interpretation of Decision Making Performance ...................................................... 9

3.2 Situation Awareness in Power Grid Control Systems .................................................................................. 10

3.2.1 Diversity of Flavors of SA in Power Grid Operations ..................................................................... 10

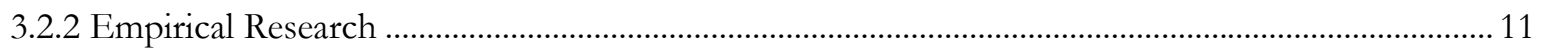

3.2.3 Tools Contributing to SA in Power Grid Operations ....................................................................... 13

4. Interviews and Examination of Blackout Transcripts ..................................................................................... 15

4.1 August 2003 Blackout Transcripts of Phone Conversations ...................................................................... 15

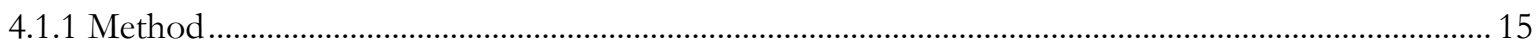

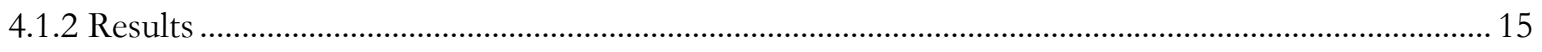

4.2 Analysis of Interviews with Experts on the Blackout ............................................................................. 17

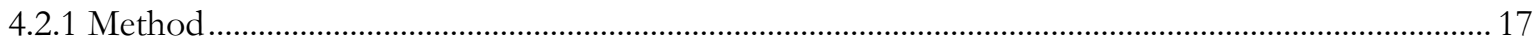

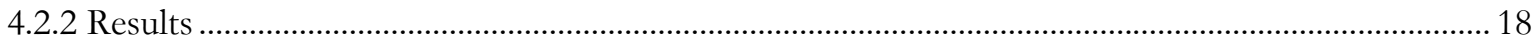

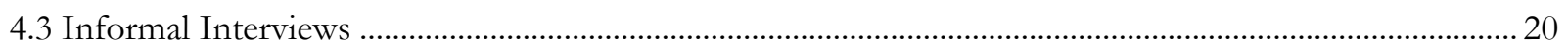

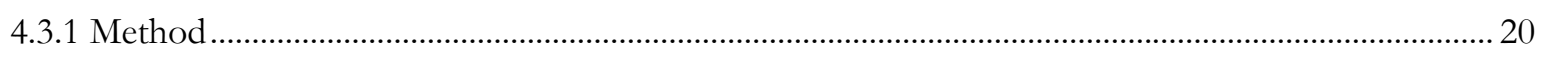

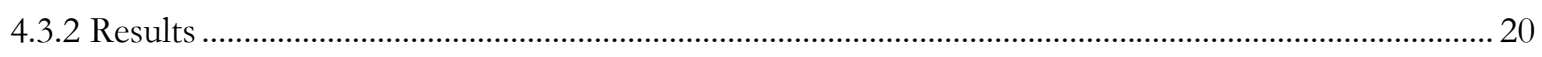

4.4 Key Concepts and Patterns from Analyses of Transcripts and Interviews ............................................ 20

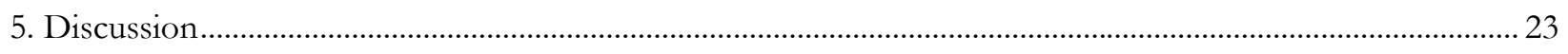

5.1 Summary of Findings from Review of Literature and Human Factors Practice ....................................2 23

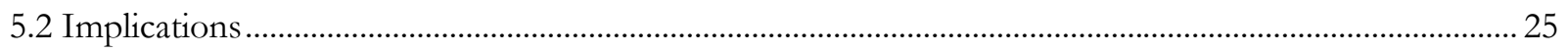

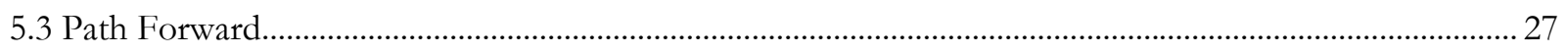

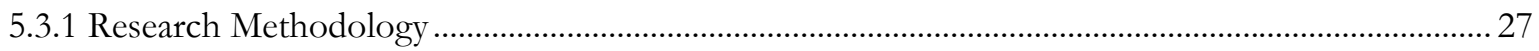

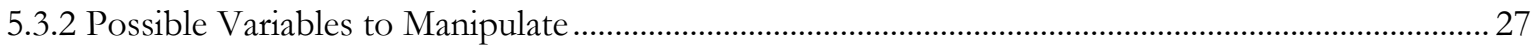




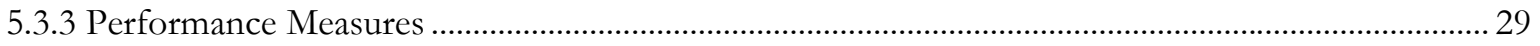

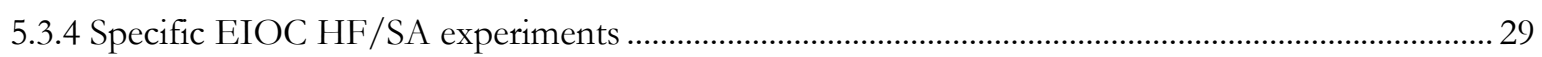

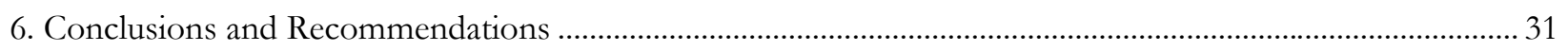

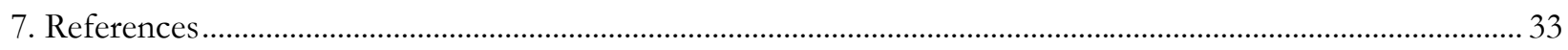

\section{Figures}

Figure 1. Taxonomy of R\&D for Power Grid HF/SA …………………............................................................. 2

Figure 2. Differing Perspectives Provide Organizing Principles for SA Theories ................................................. 6

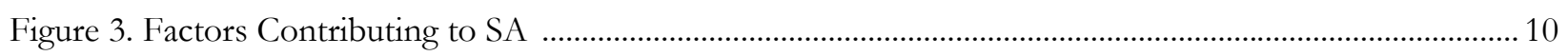

Figure 4. Example of Blackout Conversation Analysis ........................................................................................... 16

Figure 5. Relative Proportions of Information Exchanges Regarding Physical Status,

Operational Status, Handshake, or Other ........................................................................................ 18

Figure 6. Example of Blackout Interview Analysis Information Breakdown ........................................................ 19

Figure 7. Increasing SA Outside of One's Control Area Toward Shared SA .......................................................... 22

Figure 8. Taxonomy of R\&D for Power Grid HF/SA ................................................................................ 23

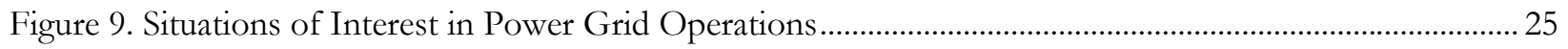

Figure 10. Example of the 'Mode Meter' visualization of oscillation damping .................................................... 30

\section{Tables}

Table 1. Supervisory Control and Monitoring in Nuclear Versus Power Grid Operations ................................... 5

Table 2. Traditional SA and Sensemaking Approach to SA Compared ............................................................... 8

Table 3. Examples of Exchanges in Blackout Transcripts on Physical and Operational Status.......................... 17

Table 4. Summary of Blackout Interview SA Concepts and Patterns..................................................................... 19 


\title{
1. Introduction
}

\author{
Situation Awareness is a well-studied but elusive concept tied \\ to human factors research on power grid operations. With \\ increasing complexity and interconnectivity of the grid, the \\ scope and complexity of situation awareness have grown, and \\ new paradigms are needed to guide research and tool \\ development aimed to enhance and improve operations.
}

\subsection{Background}

Historically, electric power system operators have performed diverse functions of operating transmission, dispatching generation, and purchasing and selling energy outside their area based on known predictable dispatch patterns. Since deregulation, complete information about the state of the power grid is seldom available to a single operator, who typically deals with only one or at most a few functional areas of power system operations. This decreased awareness of status and power flows based on market footprints makes it more difficult for operators to maintain situation awareness (SA). Additionally, because of an interconnected grid, operators must deal with increased complexity, which demands more sophisticated principals of operation.

There is an increasing need to focus on demands placed on control room dispatchers in the postderegulation environment. Operators are not able to perform their duties as effectively as they once could. Technologies such as remedial actions schemes and custom Flexible AC Transmission Systems devices require operators to understand more and more specialized details of power grid engineering and operation. Prolific amounts of data tend to distract operators more than help them and the increased need for SA within and across organizational boundaries raises many challenges, especially during emergency situations. The impact of deregulation and increased consumer electricity needs have prompted the need for a new look at human-control integration.

These new needs have not been adequately defined, systematically incorporated into daily practices, or communicated to operators through training. Moreover, the analyses of recent blackouts have clearly demonstrated the need to enhance the operator's SA despite advances in technology, which have led to overwhelming amounts of data that operators are unable to effectively assimilate.

Post August 2003 blackout, North American Electric Reliability Corporation (NERC) committees such as the Personnel Sub-Committee and the ISO-RTO Training Council began to specifically address the issues from a national level perspective. While these two groups in the summer timeframe of 2005, began to explicitly formalize strategies, requirements, and recommendations in specific areas such as SA

(NERC, 2004). They developed this starting point with very little, if any, information available to offer solutions and identified many areas of essential elements of information needed to provide further requirements and recommend robust solutions.

Research is needed to produce a framework that will systematically address issues from both near and long term perspectives. This research must identify methods to enhance the operator's working environment by addressing how humans interrelate in this environment; to each other, to technologies that are designed to aid the grid, and to organizational processes. The scope of the current effort does not allow a complete baseline analysis of current control room operations to identify human factors needs and requirements; instead, the focus of the present study is on a more systematic study of SA, a widespread problem that plays a critical role in power grid operational decision making. 
While conducting the review of research, systems, and tools as part of the present study, the authors established a taxonomy that organizes the relatively large body of theoretical and applied research in the field of human factors/situation awareness (HF/SA) in power grid operations, as shown in Figure 1. This taxonomy provides a perspective on the R\&D that has been and is continuing in the field of HF/SA for grid operations, and serves as an aid in following the discussion of research, tools/methods, and systems in the review of literature and methods presented in this report. It is also important to point out that the particular "sensemaking" perspective that we have embraced, following our review and synthesis of research in various human factors domains of study, is distinct from, but complementary to other traditional research in the human factors field that focuses on ergonomics and the transactional relationship between the human operator and the systems. ${ }^{1}$

\begin{tabular}{|c|c|c|}
\hline R\&D Area & Goal & Examples \\
\hline \&: & $\begin{array}{l}\text { Enhance SA } \\
\text { and facilitate } \\
\text { shared } \\
\text { knowledge }\end{array}$ & $\begin{array}{l}\text { - PNNL internal investment } \\
\text { of HF on SA }\end{array}$ \\
\hline $\begin{array}{l}\text { User } \\
\text { Transactions }\end{array}$ & $\begin{array}{l}\text { Improve user- } \\
\text { computer } \\
\text { interface }\end{array}$ & $\begin{array}{l}\text { - Traditional HF studies } \\
\text { - SA studies (Endsley) }\end{array}$ \\
\hline Visualizations & $\begin{array}{l}\text { Enhance or } \\
\text { speed decision } \\
\text { making }\end{array}$ & $\begin{array}{l}\text { - Overbye's experiments } \\
\text { - PNNL viz projects }\end{array}$ \\
\hline $\begin{array}{l}\text { Tools/ } \\
\text { Methods }\end{array}$ & $\begin{array}{l}\text { Enhance or } \\
\text { speed decision } \\
\text { making }\end{array}$ & $\begin{array}{l}\text { - State Estimation } \\
\text { - Contingency Analysis }\end{array}$ \\
\hline $\begin{array}{l}\text { Data Compilation \& } \\
\text { Processing }\end{array}$ & $\begin{array}{l}\text { Improve } \\
\text { computational } \\
\text { speed }\end{array}$ & - EMS \\
\hline 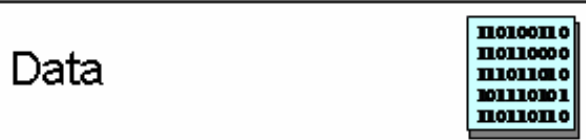 & $\begin{array}{l}\text { Improve data } \\
\text { ingest \& } \\
\text { collection }\end{array}$ & - SCADA \\
\hline
\end{tabular}

Figure 1. Taxonomy of R\&D for Power Grid HF/SA

1 This transactional relationship was described by Greitzer, Hershman and Kaiwi (1985) as a prime source of complexity in system design that "... focuses on the form and literal content of isolated transactions (e.g., friendly input/output formats) rather than their function in the larger system." As they remarked, interaction in this transactional approach is at best only locally optimal and the user is "left somehow to configure a host of local transactions to meet the [broader] system goals." 


\subsection{Objectives}

The long term objective of this research is to integrate valuable technologies into the grid operator environment that support normal and abnormal operating conditions and address non-technical barriers to enable the optimum use of these technologies. More specifically, the research aims to identify methods and principals to increase SA of grid operators in the context of abnormal system conditions that are representative or common across many operating entities and, in parallel, develop concrete experimental methods for studying technologies and operational practices which contribute to SA. 


\title{
2. Research Design and Methodology
}

\author{
The approach, informed by a cognitive science perspective, \\ takes a fresh look at the research literature, existing source \\ information on abnormal operations and events, and interview \\ documentation to establish a framework to guide empirical \\ studies within the PNNL Electricity Infrastructure Operations \\ Center to promote power grid operations situation awareness.
}

The approach gathers information from a variety of sources to address research questions such as the following:

- What information is needed to facilitate the monitoring and supervisory control of the grid by the operator?

- What information is needed for the timely formulation of appropriate actions to maintain grid stability?

- How do the operators and decision makers get the information they need, and how do they use that information?

- What are the implications of these SA factors for the design of displays, methods, tools, interaction concepts and organizational processes to facilitate $\mathrm{SA}$ and effective maintenance of grid safety, reliability and economy of operations?

Information sources that we used to identify critical factors underlying SA include interviews with experienced operational personnel, available historical summaries and transcripts of abnormal conditions and outages (e.g., the August 14, 2003 blackout), scientific literature, and operational policies/procedures and other documentation. Power grid operators-especially reliability coordinators (RCs) — are the users who represent our primary focus. Of interest are their key real-world daily operational problems/needs in communicating with other operators and RCs to produce more effective decisions, coordinate activities of operators responsible for different control areas and promote greater SA of conditions in surrounding areas.

Using these information sources, we looked for common patterns that provide insight into the situation awareness needs of operators and RCs. While there have been other studies with a similar focus, the main purpose of the present analysis is to extract and analyze possible cognitive factors affecting judgment and decision making to reveal insights and suggest new human factors-based solutions to improve SA.

The research applies proven methods in the field of human factors/cognitive systems engineering to ensure that the concepts explored address real problems and needs. Thus, a problem-driven, task-oriented approach is used to focus limited $R \& D$ resources on understanding the SA problem, creating a framework within which to design information technology and visualization concepts for establishing and maintaining $\mathrm{SA}$, and working with domain experts to devise effective technology-based solutions that address limitations of human operators and decision makers. 


\title{
3. Review of Scientific Literature
}

\author{
We argue for a new perspective on $S A$ in terms of sensemaking, \\ also called situated or ecological decision making, where the \\ focus of the investigation is to understand why the decision \\ maker(s) experienced the situation the way they did, or why \\ what they saw made sense to them at the time.
}

PNNL reviewed scientific literature from a broad range of application domains, certainly focused on power grid operations but also including military command/control, nuclear power, aviation and other domains of research on human factors/situation awareness. The fact that there are more similarities than differences enables us to borrow freely from the vast body of research on SA across these domains. Nevertheless, there are some differences that ought to be acknowledged and kept in mind as the research and empirical studies are examined. Of most relevance perhaps is a distinction between the human factors issues of nuclear power plant operations versus electric power grid operations. It may be tempting to adopt solutions developed for improving SA in nuclear power plant operators in the United States to improve SA and the supervisory control and monitoring performance of power grid system operators. However, there are specific differences in the two operational environments that may lead us to question the wisdom of directly transferring what is known about enhancing the SA of the nuclear power grid operators to the domain of power grid operators. Table 1 summarizes these differences.

Table 1: Supervisory Control and Monitoring in Nuclear Versus Power Grid Operations

\begin{tabular}{|l|l|}
\hline \multicolumn{1}{|c|}{ Nuclear Power Plant Operations } & \multicolumn{1}{c|}{ Power Grid Operations } \\
\hline $\begin{array}{l}\text { Operate a closed loop system - Nuclear } \\
\text { power plant operators, until recently, "area of } \\
\text { responsibility" is the power plant's health --- } \\
\text { the complex systems that are involved in } \\
\text { generating the power. }\end{array}$ & \begin{tabular}{l} 
- $\begin{array}{l}\text { Operating an open loop system -Power grid } \\
\text { operators "area of responsibility" while it is } \\
\text { specific it is connected to many other sys- } \\
\text { tems that are outside the area of response- } \\
\text { bility. These outside systems impact what } \\
\text { happens to the systems the power grid } \\
\text { operators is responsible for. }\end{array}$ \\
\hline $\begin{array}{l}\text { Monitoring and control of hardwired } \\
\text { instrumentation }\end{array}$
\end{tabular}$\quad \begin{array}{l}\text { Monitoring and control of digital , distributed } \\
\text { instrumentation }\end{array}$ \\
\hline
\end{tabular}

\subsection{Situation Awareness Theories and Models}

There is a large body of literature in HF/SA R\&D and this continues to be an active area of research. In this brief overview of SA theories, we can only provide a cursory discussion of a complicated domain. Figure 2 situates the various conceptualizations or organizing principles for SA in terms of differing theoretical perspectives that have been advanced - state versus process conceptualizations, operator-focused versus situation-focused viewpoints, and a sensemaking perspective. This provides an organization for the following subsections that describe SA theories; referring to the figure may aid in understanding the relationships among the theories that are discussed. 


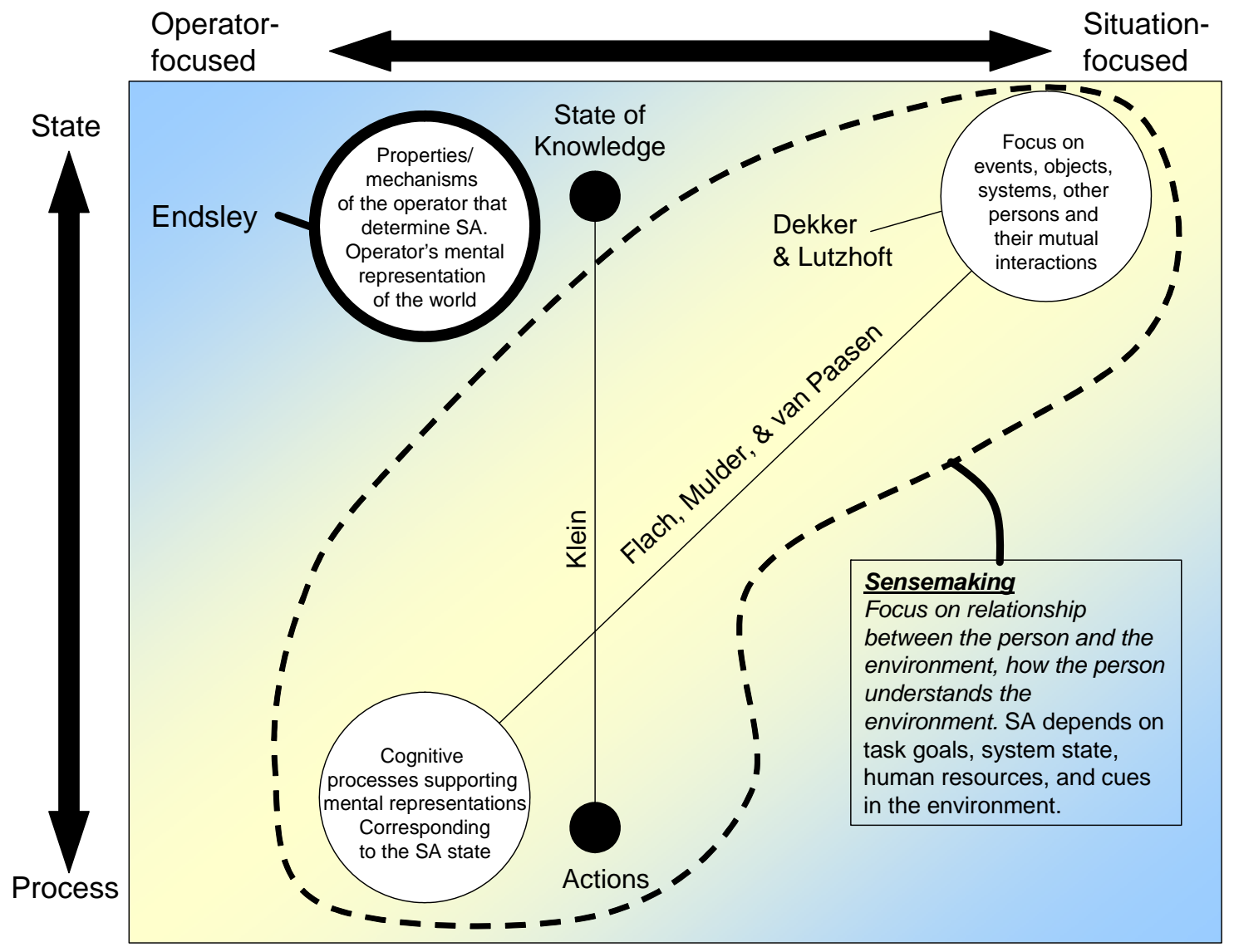

Figure 2. Differing Perspectives Provide Organizing Principles for SA Theories

\subsubsection{States Versus Processes}

It has been widely established that SA is a contributing factor to many commercial and government accidents and incidents in a variety of contexts. ${ }^{2}$ However, defining exactly what constitutes SA has been a challenging task because of the complexity in characterizing the construct in terms of a set of psychological processes. As Banbury and Tremblay (2004) have observed, “...the major impetus of research [on SA] has been on the development of techniques to measure SA, at the expense of a more rigorous understanding of why SA varies under certain psychological and environmental conditions." (p. xiv).

Rousseau, Tremblay, \& Breton (2004) performed a systematic classification of 26 SA definitions in the literature. The definitions turned out to be evenly divided in two classes corresponding to what is now a generally accepted duality of SA as a State or a Process. Micah Endsley $(1988,1995)$ has provided the most highly recognized descriptive model of SA. Endsley's well-known SA definition describes SA as the perception of the elements in the environment within a volume of time and space, the comprehension of their meaning, and the projection of their status in the near future. Thus, Ensdley uses the term to define a state of knowledge (she describes the associated process as situation assessment). Endsley's model includes two parts: a core SA model, and a set of factors affecting SA. The core SA model is the basis for much of the current thinking about SA. It is a three level system comprising Level 1, Perception of the elements in the environment; Level 2, Comprehension of the current situation; and Level 3, Projection of future states. The Perception level is the

\footnotetext{
2 For example, the Three Mile Island accident; the USS Vincennes downing of a commercial aircraft.
} 
first step in achieving SA. In cognitive terms, this level involves interaction with long-term memory (comparing the information elements with what is already known); it is under attentional selection (modulated by the operator's selective attention processes as determined by task requirements); and the information content is held in active working memory. The Comprehension level provides an organized picture of the elements with a comprehension of the significance of objects and events. In cognitive terms, mental models stored in longterm memory provide a basis for Level 2 SA. The Projection level enables predictions about the states of the environment in the near future. This is achieved through knowledge of the status and dynamics of the elements and comprehension of the situation. In this view of SA, stimuli (information elements) are processed to yield meaning, and a common "solution" to human information processing limitations is to design methods to facilitate processing of more information through limited processing channels.

An alternative to the above information processing conceptual framework is to consider SA as a label for a range of cognitive processes or processing activities. For example, Dekker \& Lutzhoft (2004) take issue with the "empiricist" view of SA that breaks down the process into perception of "elements" and describe an ecological view of SA where awareness is an intrinsic feature of the functional relationship between the environment and the person. Their perspective is consistent with current ideas about sensemaking as an active strategy for dealing with a complex world. Dekker and Lutzhoft observe:

When looked at from the position of retrospective outsider, the 'deficient SA' can look so very real, so compelling. They failed to notice, they did not know, they should have done this or that. But from the point of view of people inside the situation, as well as potential or other observers, these deficiencies do not exist in and of themselves; they are artifacts of hindsight, 'elements' removed retrospectively from a stream of action and experience. To people on the inside, it is often nothing more than normal work. If we want to begin to understand why it made sense for people to do what they did, we have to put ourselves in their shoes. What did they know? What was their understanding of the situation?

(Dekker \& Lutzhoft, p. 40)

This is a strong condemnation of the element-oriented/state-of-knowledge based definition of Endsley. They contend that a side effect of using the information processing metaphor is that SA is seen as a problem of getting more information (more data, more "elements") into people, and more information processed through their limited processing channels. While the sensemaking perspective on SA may acknowledge the existence of "elements," its focus is on the role they play in constructing a plausible "story" of what is going on (sensemaking), not for building an accurate mental model of an external world. Dekker and Lutzhoft observe that few theories of SA acknowledge this, instead directing their attention to the creation of meaning from elements and the future projection of that meaning. Thus, in studying SA, rather than examining the lack of correspondence between actual and experienced worlds (a retrospective exercise), one should examine the decision makers' "unfolding experience of the situation in which they found themselves." Table 2 provides a brief comparison of approaches to SA based on more traditional information processing interpretations versus a sensemaking perspective.

Sensemaking is the ability or attempt to make sense of an
ambiguous situation. It is the process of creating situational
awareness and understanding to support decision making under
uncertainty. It is an effort to understand connections among
people, places, and events in order to anticipate their
trajectories and act effectively (Klein et al., 2006).


Table 2. Traditional SA and Sensemaking Approach to SA Compared

\begin{tabular}{|c|c|c|}
\hline & Traditional SA Approaches & Sensemaking SA Approach \\
\hline What it is... & $\begin{array}{l}\text { Human's mental representation } \\
\text { of the world-perception/ } \\
\text { comprehension of elements in } \\
\text { the environment. }\end{array}$ & $\begin{array}{l}\text { Cognitive and systemic approach to } \\
\text { understanding the decision maker's } \\
\text { unfolding experience, constructing a } \\
\text { plausible story of what made sense at } \\
\text { the time. }\end{array}$ \\
\hline Focus & $\begin{array}{l}\text { Focus on what was failed to be } \\
\text { noticed, what was not known, } \\
\text { and what was not done. }\end{array}$ & $\begin{array}{l}\text { Focus on relationship between the person } \\
\text { and the environment, within the context of } \\
\text { task goals, system state, human } \\
\text { resources, and elements in the } \\
\text { environment. }\end{array}$ \\
\hline Would seek to answer... & $\begin{array}{l}\text { What information is needed to } \\
\text { solve the problem? }\end{array}$ & What is the underlying cause of problem? \\
\hline $\begin{array}{l}\text { Finds solutions to } \\
\text { problems by... }\end{array}$ & $\begin{array}{l}\text { Identifying missing information } \\
\text { that would have prevented the } \\
\text { problem }\end{array}$ & $\begin{array}{l}\text { Help the decision maker understand what } \\
\text { matters, see relationships. Identify how } \\
\text { skilled decision makers decompose com- } \\
\text { plex information into coherent chunks, and } \\
\text { what might contribute to poor judgments. }\end{array}$ \\
\hline $\begin{array}{l}\text { Addresses Problems } \\
\text { through... }\end{array}$ & $\begin{array}{l}\text { Present more information, look } \\
\text { for interaction/display designs to } \\
\text { help process more information } \\
\text { through limited human infor- } \\
\text { mation processing channels. }\end{array}$ & $\begin{array}{l}\text { Provide priorities and clarity to help deci- } \\
\text { sion maker understand what matters. } \\
\text { Address awareness, processes, proce- } \\
\text { dures, communications, thought } \\
\text { processes. }\end{array}$ \\
\hline $\begin{array}{l}\text { Example: MISO State } \\
\text { Estimator not running } \\
\text { properly and not updated } \\
\text { every } 5 \text { minutes- } \\
\text { undiscovered for several } \\
\text { hours prior to Aug. 14, } \\
2003 \text { blackout. }\end{array}$ & $\begin{array}{l}\text { Fix Training. Fix the State } \\
\text { Estimator. Require that new } \\
\text { TRO or ISO operation not be } \\
\text { approved until it has verified } \\
\text { reliable functionality of all its } \\
\text { capabilities. }\end{array}$ & $\begin{array}{l}\text { Address systemic causes-cross valida- } \\
\text { tion of instruments, cross checks by } \\
\text { personnel. Establish additional/redundant } \\
\text { ways to share status information to ensure } \\
\text { that inconsistencies will be noticed. }\end{array}$ \\
\hline
\end{tabular}

\subsubsection{Operator-Focused Versus Situation Focused}

There is not a clean separation between the conceptualizations of SA as a state versus a process, and its treatment in the literature has been somewhat inconsistent. For example, Klein's work indicates that situation assessment is a very broad concept that covers situation awareness content (as defined by Endsley) as well as actions (process). A possible source of confusion is that the different points of view reflect two different basic approaches to the question of SA. One approach is operator-focused and it concerns the properties/ mechanisms of the operator as they determine SA. The other approach, is situation-focused, holds that SA is determined by the environment or situation in which the operator works. This latter perspective resets the issue of SA definition around two basic factors on which SA depends-a state oriented definition may be associated with a situation focused approach and characterized as driven by properties of the situation; while a process oriented definition associated with an operator-focused approach would be centered on properties of the operator. This helps to reframe the classical state-process distinction into an operator-focused versus situation-focused context.

The operator-focused approach is concerned with the set of cognitive processes supporting the production of mental representations corresponding to the SA state. Such processes are by definition a property of the human operator. This approach follows an information-processing framework that considers a mental representation of the world to be based on processing with specific functions-e.g., perception, compre- 
hension, and projection (as defined by Endsley, even though she prefers to talk about state rather than process); or information extraction, information integration, mental picture formation, and projection/ anticipation. However, most of the process-based definitions do not follow generally accepted human information processing models that identify a network of processes like perception, attention, and memory.

The situation-focused approach is concerned with mapping relevant information in the situation onto a mental representation of that information within the operator. State-oriented definitions limit the description of processes involved in SA, in line with Gibson's fundamental concept of direct perception that involve such principles as: (i) all information necessary for perception is contained in the environment and (ii) perception is immediate and spontaneous. This implies that in order to understand perception, the priority must be on understanding the environment (independent of underlying processes). The situation focused approach provides a basis on which to define SA as a state: The situation can be defined in terms of events, objects, systems, other persons and their mutual interactions. This is domain dependent. Thus, a situation may be defined as a set of environmental conditions and system states with which the participant is interacting that can be characterized uniquely by a set of information, knowledge, and response options. SA should then integrate five aspects of the situation: the surrounding environment, the mission's goals, the system, the available physical and human resources, and (if applicable) the team. In this view, situation takes a very broad meaning, including task and mission features as well as other human agents in the environment. It is much more than awareness of the distribution in space of objects within a contextual environment. It has to include task goals, criteria of performance, and cues in the environment.

\subsubsection{Implications for Interpretation of Decision Making Performance}

The traditional information processing/empiricist view of SA (e.g., Endsley's definition) compels the investigator to (retrospectively) identify what the decision maker(s) failed to notice, what they did not know, or what they should or should not have done. In contrast, the sensemaking perspective suggests that it is not about providing more information (more data, more elements), but rather about providing priorities and clarity about preferences to help the decision maker understand what matters (Weick, 1995, p. 27). Thus, from the point of view of the decision maker in the situation, deficiencies such as failures to notice an element in the environment or perform a critical action may not even exist — they may be artifacts of retrospective hindsight.

This cognitive/ecological approach to SA is a refreshing and potentially enlightening framework within which to study SA and explore more effective solutions to information presentation/visualization within the power grid control system environment. This perspective leads us to ask different questions and to focus on understanding underlying cognitive processes of sensemaking - transactions between goals, observations, and actions - rather than on more superficial questions about the extent to which certain human information processing limitations, display characteristics or visualization concepts might contribute to loss of SA. Consider, for example, the frequently-cited human limitation described as Miller's (1956) magical number seven, plus or minus two: Miller's insightful observation that humans have a limited capacity in the number of items or "chunks" of information they can maintain in working memory tends to be interpreted as a hard limitation (information processing bottleneck). This factor is clearly situation-dependent, and research has shown that experts have the ability to reduce complex stimuli into coherent chunks so that the $7 \pm 2$ constraint is rarely a limit on expert performance in natural environments. Flach, Mulder, and van Paasen (2004) observe that poor SA refers to the inability of a decision maker to see what matters. In this context, poor SA reflects the lack of a basis for decomposing complex data or information into coherent chunks. As they suggest, a useful model of SA should suggest how skilled decision makers might chunk information so they can navigate smoothly through the problem space, and it should suggest where they might make poor judgments and interpretations or how a novice's understanding of a situation would differ from that of an expert. Further, such a normative model should also suggest user interface and training interventions. In the case of interface design, the goal is to make more explicit connections across levels of abstraction to improve awareness of patterns and relationships (Flach, Mulder, and van Paasen, 2004). 


\subsection{Situation Awareness in Power Grid Control Systems}

\subsubsection{Diversity of Flavors of SA in Power Grid Operations}

Section 3.1 described the complexities and divergent concepts that can be encompassed by the concept of SA in general. Similarly, delving more specifically into SA in power grid operations reveals furthers levels of complexity. The scope and breadth of SA that any given human actor in power grid operations has or needs depends on many factors. Figure 3 illustrates three basic contributors to SA-Human, Information, Machine and (or physical system) — and the additional influences of the environment, the organization, and the human's roles and responsibilities.

Setting aside questions regarding the physical system, the information about it, and the human's interaction with that information and that physical system, the roles and responsibilities of humans in this system affect their perspective on SA, because SA can be closely linked to a person's goals or objectives and past experience. The type of SA he/she needs and the tools or methods that can be used to improve that SA can vary greatly depending on his/her geographic responsibility, grid level responsibility, time dependency of responsibility, and functional responsibilities:

- Geographic. An actor in power grid operations needing SA may be responsible for a small control area, multiple control areas, a large region within a state, or a vast multi-state region. For example, the time required for a significant weather front to move across a large region as compared to a small control area would result in different SA requirements for the two. The SA of a person operating a large region may need to map to a vastly more complex mental picture of the physical system and involve many more actors.

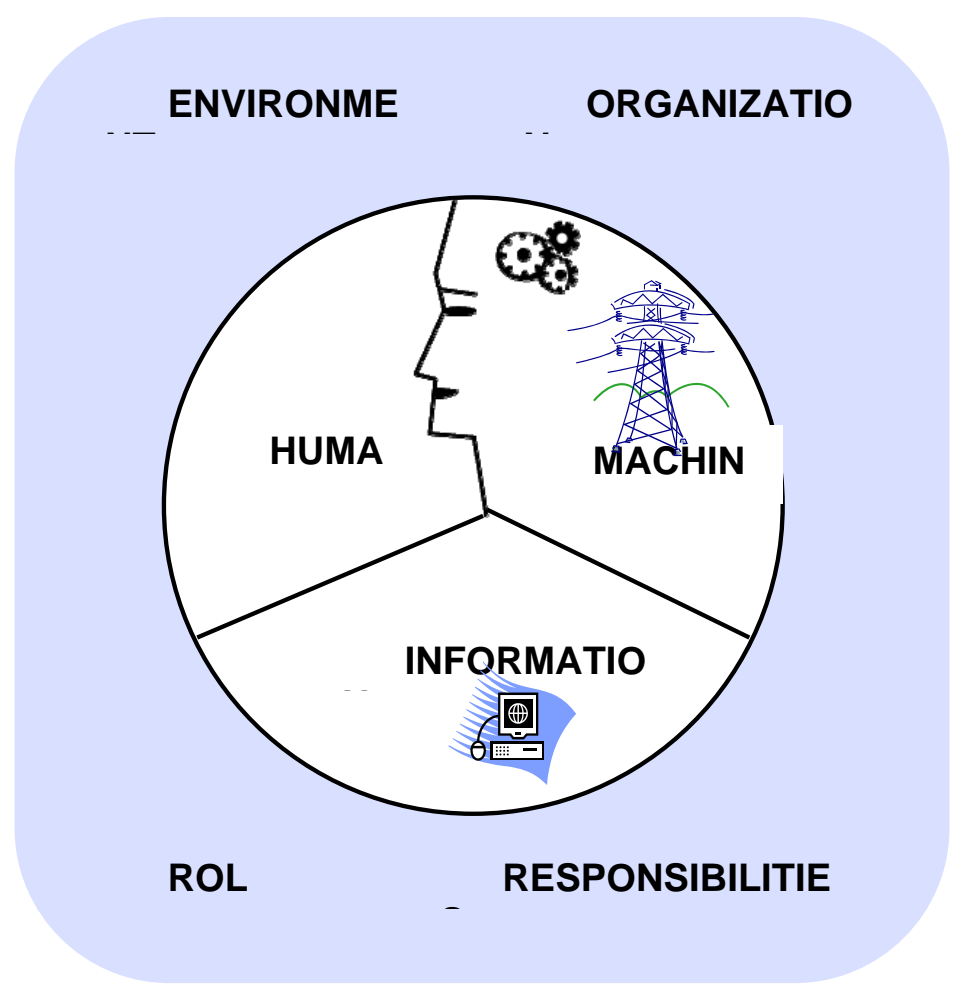

Figure 3. Factors Contributing to SA 
- Grid level. Responsibility for grid operations is often separated from distribution level, to lower voltage transmission lines (e.g., up to $235 \mathrm{kV}$ ), to high voltage transmission lines, to a supervisory level. Operators at these different levels are often concerned about different factors; for example, a transmission operator may not need to be aware of voltage issues in the distribution system.

- Time. Time scales of human grid operation can vary from sub-seconds or minutes (e.g., realtime operations of dispatchers) to hours or days (e.g., contingency planning of operations engineers) to weeks or months. SA needs may vary considerably if a planning or operations engineer is maintaining SA to run state estimations for contingency plans (not a real-time need) as opposed to an Redial Action Scheme (RAS) dispatcher trying to maintain SA under the pressure of a 20 minute count down clock and threat of financial penalties.

- Functional. At any one of these geographic, grid level, and time scales, the complexity of operations may be such that different roles are created and separated across distinct, though sometimes overlapping, operators. For example, in BPA control center operations, you may find systems dispatchers handling voltage control, switching and outages, $\mathrm{RAS}$ (Remedial Action Scheme) dispatchers implementing and managing procedures for specific contingencies, $A G C$ (Automatic Generation Control) dispatchers handling frequency control, and senior shift dispatchers (supervisors), maintaining awareness of the overall picture and coordinating. Similarly, regional reliability coordinators have responsibilities for monitoring and coordinating to meet reliability objectives, quite different from market driven goals of, for example, generation facility operations.

In sum, while studying SA in power grid operations it is very important to be aware of the breadth of situations and huge diversity of tools and functions that fall under the umbrella of 'power grid operations'. Within this broad umbrella, our analysis leads us to focus on maintaining high-level, geographically broad situational awareness, which is not the same and does not involve the same needs or processes and finetuning or minute-by-minute adjusting of situational awareness while operative actions are being taken. The human factors experiments which we introduce in Section 5 and which will be implemented in year 2 of this research must acknowledge this complexity and be designed to address these two different levels of SA. The aim will be to develop and demonstrate experimental techniques which can be applied across a variety of situations and tools.

\subsubsection{Empirical Research}

Within this broad context of power grid operations and SA theoretical perspective, we review some of the more prominent empirical studies of SA in power grid control systems, with an aim to illuminate issues and gaps in this area of research that we seek to address in the present study.

Professor Thomas J. Overbye and his colleagues have conducted a series of informative experiments investigating various user interface strategies for effective visualizations of power system status (Overbye, Meliopoulos, Wiegmann, and Cokkinides, 2005). They proposed and studied 2- and 3-dimensional visualizations to help power system engineers and operators more quickly understand the potentially overwhelming amount of data that are available. This information includes a global view of the system static security level in terms of the contingency analysis (CA) voltage magnitudes at buses and loadings on the monitored transmission elements, the locations of vulnerable power system elements and the severe contingencies, and the geographical relationships between contingent limit violations and the contingencies themselves. The visualizations identified low voltages, but high voltage violations could be displayed using the same approach. In situations where both high and low voltage violations are of concern, they could be distinguished by different colors, for example, blue for low voltages and violet for high voltages. The worst voltage violation for each contingency or each bus, as conveyed by the cylinder in contingency severity displays and the reversed cone for the bus in power system element vulnerability displays, could be defined as the voltage magnitude deviating from the nominal level the most for the contingency or at the bus. These 
visualizations are not intended to replace the traditional tabular displays for contingency analysis results, but rather to supplement such lists. Tabular displays can be integrated into these visualizations when numerical values are needed. Overbye and colleagues also conjectured that such visualizations could be augmented to include information about the location of candidate controls to correct the contingent limit violations. For voltage violations, candidate controls could be the reactive power reserve of generators, LTC transformers, and available switched shunts of SVC devices. Example controls for overload correction could include generators with controllable real output, phase shifters and other power electronics devices such as UPFC and IPFC. A second extension would be the consideration of multiple device and sequential outage contingencies. One potential approach would be to just define additional one-line "elements" representing the multiple device contingencies. For example, if a contingency involves opening three lines sharing a single right-of-way, the new contingency element could be shown on the one-line parallel to the three lines.

Overbye and colleagues conducted formal human factor experiments to evaluate the effectiveness of several power system visualizations: pie charts to visualize line flow, animated visualization of transmission line flows, animated visualization of power transfer distribution factors (PTDFs), and the use of 3D to show generator real power outputs. Experiments looked at the impact of motion (animation) on power systems visualizations as well as $3 \mathrm{D}$. The key results were (a) the use of pie charts did not improve overall solution times but did result in solutions with fewer errors; (b) for line violations the use of animated arrows improved solution time and accuracy for contingencies causing multiple violations; (c) the use of pie charts with animated arrows resulted in better results than either alone; (d) the use of animated arrows for PTDF visualization results in quicker and more accurate task completion; and (e) the visualization of $3 \mathrm{D}$ generators results in quicker and more accurate task completion compared to comparable $2 \mathrm{D}$ visualizations.

In the context of SA factors, the research conducted in these detailed human factors studies shed light on some perceptual/cognitive factors affecting the effectiveness of several creative approaches to information presentation and visualization to support power grid contingency analysis and decision making, but questions and concerns remain on several levels. The visualization concepts that have been studied reflect alternative formats for presenting existing information-i.e., information that is already available but not in easily digestible form. As such, we categorize this type of research in the visualization category of Figure 1, shown earlier; these are useful studies but we suggest that more fundamental questions concern whether or what information is required that is not currently available. Other concerns regarding the experiments include the issue that the population of experimental participants is that of college students, not experienced operators. As we suggested in the previous section, the cognitive processes and limitations observed for novices may not reflect those of experienced professionals. Further, such visualizations and the tasks studied in the laboratory, while suggestive, may not adequately reflect the problem space and pace of analysis/processing that are operating in real-world power grid operational decision making. For these reasons, we have proposed the present research program to complement and extend previous research aimed at establishing a deeper understanding of the decision making process, SA factors, and associated displays/visualizations to facilitate and enhance performance.

To develop a more complete understanding of these issues, a multifaceted research program is needed that integrates (a) experimental results on visualizations for SA, (b) results of audits conducted and causal analysis studies (e.g., root cause analysis) of current operations and past incidents, (c) interviews with power grid operators to gain insight on information processing and communications challenges in maintaining SA, and (d) observations of decision making performance by experienced operators in realistic settings. For the latter approach, an effective and successful interview-based methodology is (e) cognitive task analysis (Gordon and Gill, 1997; Chipman, Schraagen, and Shalin, 2000); and a promising empirical approach to assess proposed decision aids or displays/visualizations is to employ (f) simulations and manipulation of human factors concepts within behaviorally-instrumented test environments. The Electricity Infrastructure Operations Center (EIOC) at PNNL provides just such a test environment to support empirical studies with simulated (and actual) data and experienced power grid operators. One prospective strategy for research on human factors/SA at PNNL is to engage the EIOC in empirical studies (method f, above), employing informed information display concepts derived from foundational research (methods $a$ through $e$, above). 


\subsubsection{Tools Contributing to SA in Power Grid Operations}

Given the diversities of roles and responsibilities of grid operators as described above, there is a corresponding diversity of information and tools available to help establish and maintain SA. We have assembled a non-exhaustive list of tools that are representative of each of the levels we have defined in the "Taxonomy of R\&D for Electric Power Grid Human Factors" (Figure 1). Each angle of grid operations (e.g., control room dispatchers, reliability coordinators, operations engineers...) may have access to and rely on one or many of these sources of information along with many others.

At the data level, various sources of data feed into processing systems, are combined with models and algorithms in tools and presented through a multitude of displays for users. The extent of availability and timeliness of data may vary greatly from one control area to another and one region to another. Examples are:

- Direct telemetry from transmission and distribution equipment, usually acquired through a largescale, distributed measurement and control system called Supervisory Control And Data Acquisition (SCADA). The 'completeness' and reliability of SCADA data can depend on many factors such as the degree of substation automation in a region

- Data exchanged across wide area networks between control areas (e.g., indirect telemetry data), generally called ICCP data for "Inter-Control Center Communications Protocol". The completeness and access to ICCP data from one control area to another can depend on many factors, for example, on exchange agreements between the control areas.

- Phasor data from phasor measurement units, based on a relatively recent technology designed for wide-area monitoring of the power grid, with a much higher sampling rate than SCADA data.

- Environmental data covering factors such as weather status or lightning strikes.

- Estimated data (as opposed to measured values from SCADA and phasor systems) from State Estimators is also seen (and used by other software) similarly to more 'real' data. Estimated data is needed for a number of reasons, such as to accommodate for sparse or unreliable SCADA data is some parts of the grid.

At the data compilation \& processing level, the primary tool for data compilation and processing is an Energy Management System (EMS). Quite an array of EMS systems are installed and operating across power grid operating organizations, representing a variety of vendors, different product lines, in-house developments, and different generations of products. EMS systems usually also support numerous tools, power system models, and visualization software.

At the Tools/Methods level, different software systems address different functional needs in power grid operations. Some tools support extensive modeling of the power grid; others are designed to support specific needs such as for energy marketing or for reliability assessments. Examples of tools and methods used in power system software include:

- Contingency Analysis, used to run 'what if style scenarios for operations planning.

- Power flow and system modeling software used for operations planning, such as EPRI OTS, Power World load flow scenario calculations and GE's Positive Sequence Load Flow Software.

- Interchange Data Calculator (IDC), used as a decision support tool in determining how to relieve transmission system congestion.

- Fault Locator systems, for detecting, recording, and localizing faults. 
At the level of visualizations, many different visualization tools may be integrated in any EMS system, or visualization tools may be separate packages that can be grafted on top of EMS systems and various software tools and models. Examples of visualizations are endless:

- EMS drill down, data driven, tabulated charts

- Engineering visualization authoring tools such as PI diagrams

- Power World visualization software for displaying flows, voltage contour maps, 3D overlays, etc.

- Numerous tools under development to supplement traditional black screen energy management system displays, such as PNNL’s "Green Grid", "Phasor State Estimator" (PaSE), "Spectal Analyzer", and "Mode Meter"; and also AREVA's "eterra-vision" and EPG's real time dispatcher monitoring system (RTDMS).

At the level of user transactions, a variety of screen manipulation tools and control display layouts has been developed. Some human factors studies have focused on user transactions in an effort to improve the design of visualization tools [e.g., see the discussion of Overbye's research in Section 3.2.2].

Very few decision support or operator support mechanisms exist to assist power grid operators at the Sensemaking level. One example of a somewhat formalized mechanism at this level is the WECCNET e-mail notification system which allows posting of key events, actions and observations so that the information can be shared with outside control areas. 


\title{
4. Interviews and Examination of Blackout Transcripts
}

\author{
Consistent with our findings from the literature review, our \\ analysis of August 2003 blackout transcripts and interviews \\ recognized an over-arching need to focus $S A$ research on \\ issues surrounding the concept of shared knowledge; e.g., \\ awareness of what is happening in adjacent areas as well \\ as one's own area of responsibility. Applied research impli- \\ cations are discussed.
}

\subsection{August 2003 Blackout Transcripts of Phone Conversations}

With the objective of trying to better understand the information needs of power grid dispatchers and reliability coordinators reflecting the grid situation outside of one's control area, we reviewed documentation about the August 14, 2003 blackout including the official report and the transcripts of phone conversations. ${ }^{3}$ This documentation was valuable and relevant to our research study as it represents a case study of actual events that transpired to resolve anomalies: a serious event that started to unfold but was resolved, serious but considered normal, normal operations, the identification of a unique and serious problem that was catastrophic (the blackout) and restoration. The analysis aimed to identify what types of information were exchanged or sought about conditions outside of one's area of control. Transcripts of conversations leading up to the blackout, while the blackout propagated, and during the restoration phase were included.

\subsubsection{Method}

Eight sets of transcripts (A-H) comprising a total of 619 pages capturing conversations on 6 different channels between over 50 organizations and over 400 unique speakers all occurring between 10:00 - 17:18 on August 14, 2003. Transcripts were reviewed to extract and categorize sub-conversations demonstrating information exchange related to SA such as operators sharing information between each other to establish the status of the grid and coordinating activities. We identified and extracted nine relevant conversations for more detailed analysis. These were chosen because they represented frequently reoccurring activities. The information exchanges in the sub-conversations were tabularized to establish a detailed breakdown of the reason for the information exchange, and with a particular attention to situation awareness needs outside an operator's area of responsibility.

The tabularized data are illustrated in the Figure 4. The keywords and patterns of information exchange were distilled from the detailed breakdown.

\subsubsection{Results}

Analysis of the blackout phone conversations revealed two very different types of substantive information exchanged across control areas (other types of information exchanges are important also, but related to nonsubstantive issues such as "greetings", "handshake", etc.). First, many calls focus on the current physical status of the grid. Second, other calls focus on what we might call the system's operational status-e.g., what operational actions and decisions are underway, what changes are expected or have been put in motion, what

\footnotetext{
3 See http://energycommerce.house.gov/reparchives/108/Hearings/09032003hearing1061/hearing.htm
} 


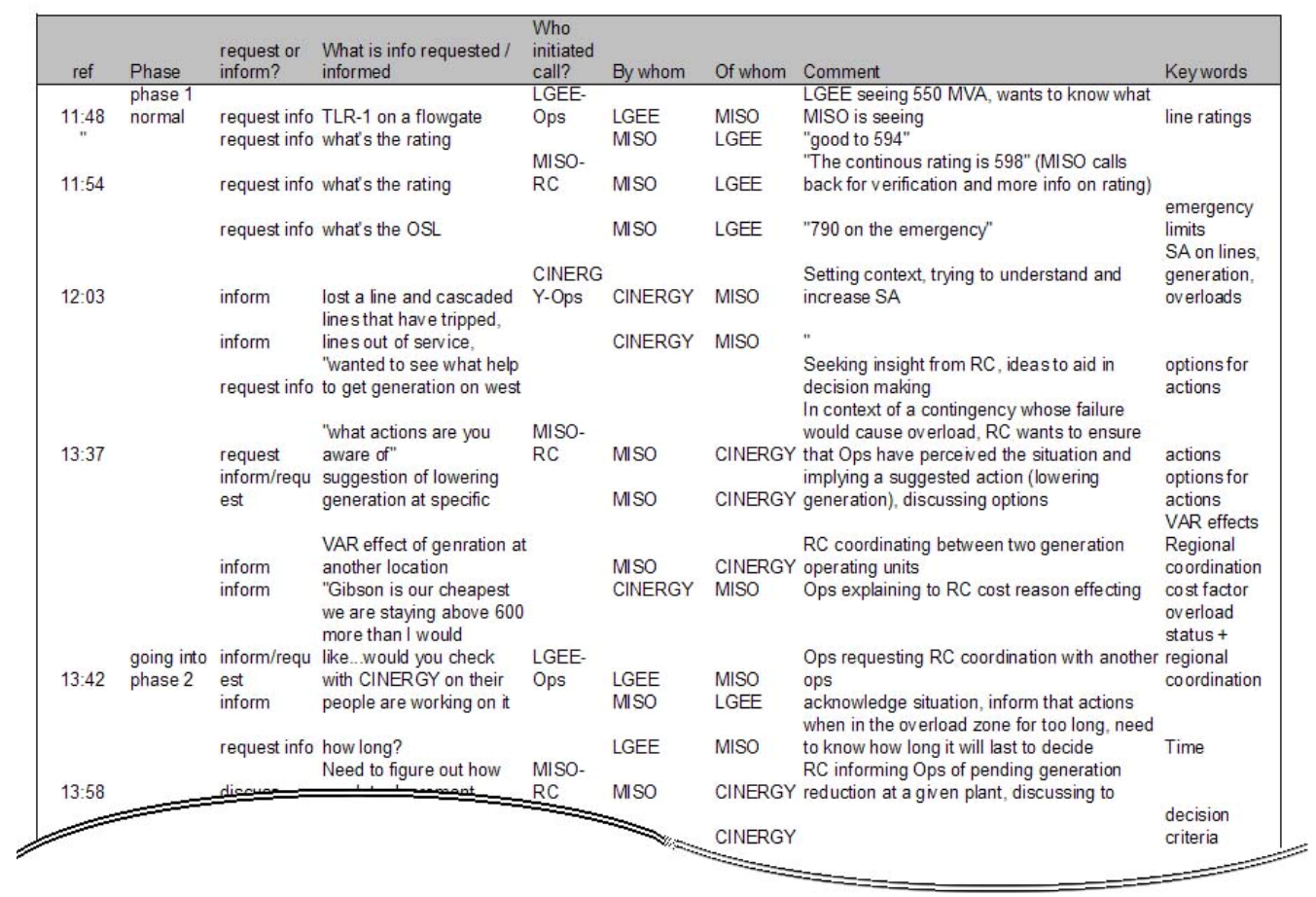

Figure 4. Example of Blackout Conversation Analysis

is the mindset of the operators in neighboring areas of responsibility. Thus, we see two distinct aspects of situational awareness: SA of the physical grid system and SA of ongoing system operations. Table 3 provides representative examples of these two types of information exchange.

In the analysis of transcripts, we observed data relating to serious problems, not related to blackout, as well as data relating to the blackout. The transcripts indicate that events moving toward Out-of-Limit conditions are resolved by both RCs and Balancing Authority Operators.(BAOs). The official report shows that they were struggling to obtain reliable information from State Estimation software/simulations, contingency analysis results, and critical status of power lines (line trips, outages, violation conditions, etc.) relating to status of systems outside their areas. These findings confirm our original LDRD focus/thrust that identifies the lack of shared information across control areas as a major factor in the failure of situational awareness and the ultimate cascading effects leading to the blackout.

Figure 6 shows the relative proportion of the various types of exchanges that we observed in the telephone transcripts. It is interesting to note that nearly a third of the exchanges dealt with communications about greetings and establishing if the party was talking to the right person. A significant proportion of the exchanges dealt with the physical grid status i.e. its state particularly at the moment of the information exchange. Another main theme of communications was about operators' activities-judgments and evaluations about decisions under consideration (e.g. what should be done given the state of the grid), actions planned, actions in progress, localized factors and options and coordinating activities that would affect the power grid. We observe that there are very few, if any, tools or research devoted to supporting information exchange and SA relating to operational status and the enabling of shared understanding with neighboring control areas. 
Table 3. Examples of Exchanges in Blackout Transcripts on Physical and Operational Status

\begin{tabular}{|c|c|}
\hline Physical System Status Exchanges & Operational Status Exchanges \\
\hline 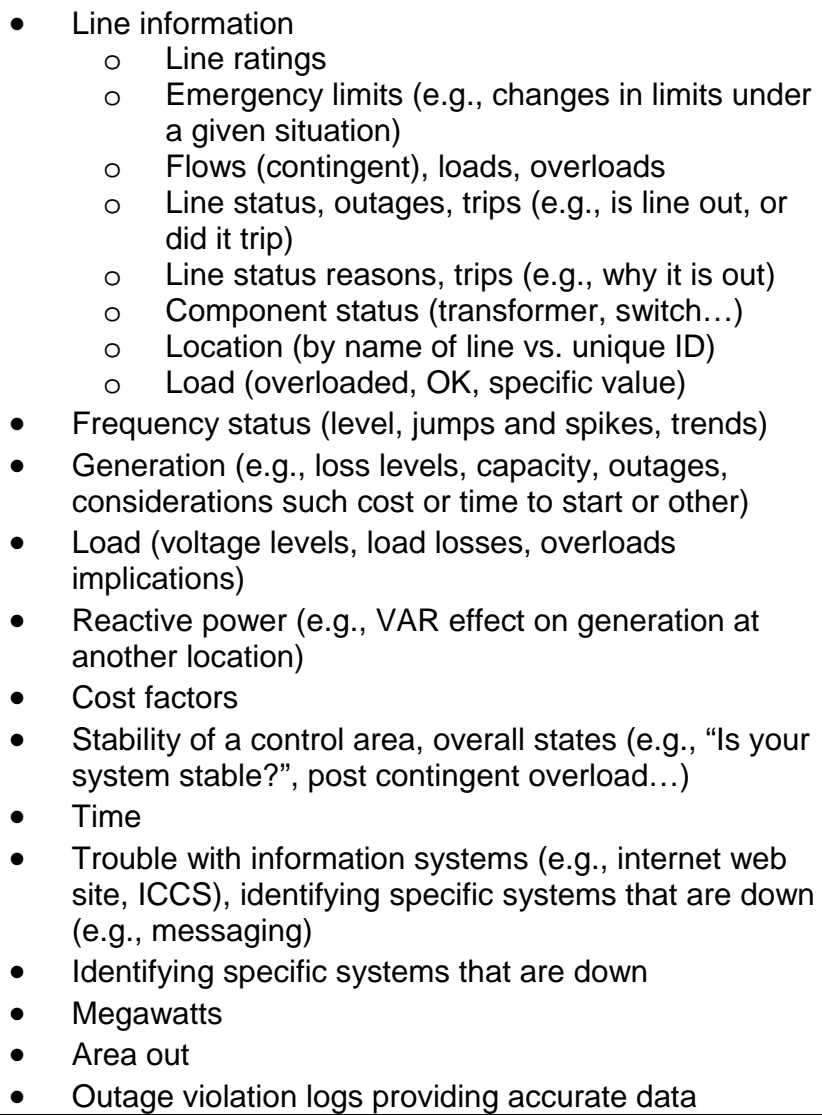 & $\begin{array}{l}\text { - } \quad \text { Significance of criteria in decision making } \\
\text { - } \quad \text { Options for actions } \\
\text { - } \quad \text { Knocted consequences of actions undertaken or } \\
\text { planned, (scheduled, scheduling)) } \\
\text { - } \quad \text { Time estimates, delays } \\
\text { - } \quad \text { Establishing mutual SA, 'group think' } \\
\quad \text { to happen) } \\
\text { - } \quad \text { Coordinating action } \\
\text { - } \quad \text { (what is going on) or action (call X) } \\
\text { - Calling in more staff to assist with bad event }\end{array}$ \\
\hline
\end{tabular}

\subsection{Analysis of Interviews with Experts on the Blackout}

The investigations of the August 2003 blackout included interviews with experts to extract lessons learned. The report identified two major causes that can be associated with situation awareness: "Cause 1, Inadequate system understanding" and "Cause 2. Inadequate Situation Awareness". ${ }^{4}$ PNNL had the opportunity to review transcripts of interviews with eight experts (including operators and RCs) involved in the Blackout investigations. We analyzed the interview transcripts to identify the information needs of power grid dispatchers and reliability coordinators reflecting the grid situation, with the same approach used for the telephone transcript analysis. The analysis aimed to identify what types of information needs were suggested by the experts, in particular regarding situation awareness outside an operator's area of responsibility.

\subsubsection{Method}

The focus of our analysis of the interview transcripts was to extract references to existing tools and information or desirable information relating to situation awareness outside of a given operator's control area. The extracted interview details were tabularized to establish a detailed breakdown of the types of information discussed by experts, the interfaces involved in information exchange, and relevant quotes from experts referring to information needs during the blackout.

${ }^{4}$ Final Report on the August 14, 2003 Blackout in the United States and Canada: Causes and Recommendations, U.S.- Canada Power System Outage Task Force, April 2004, p19. 


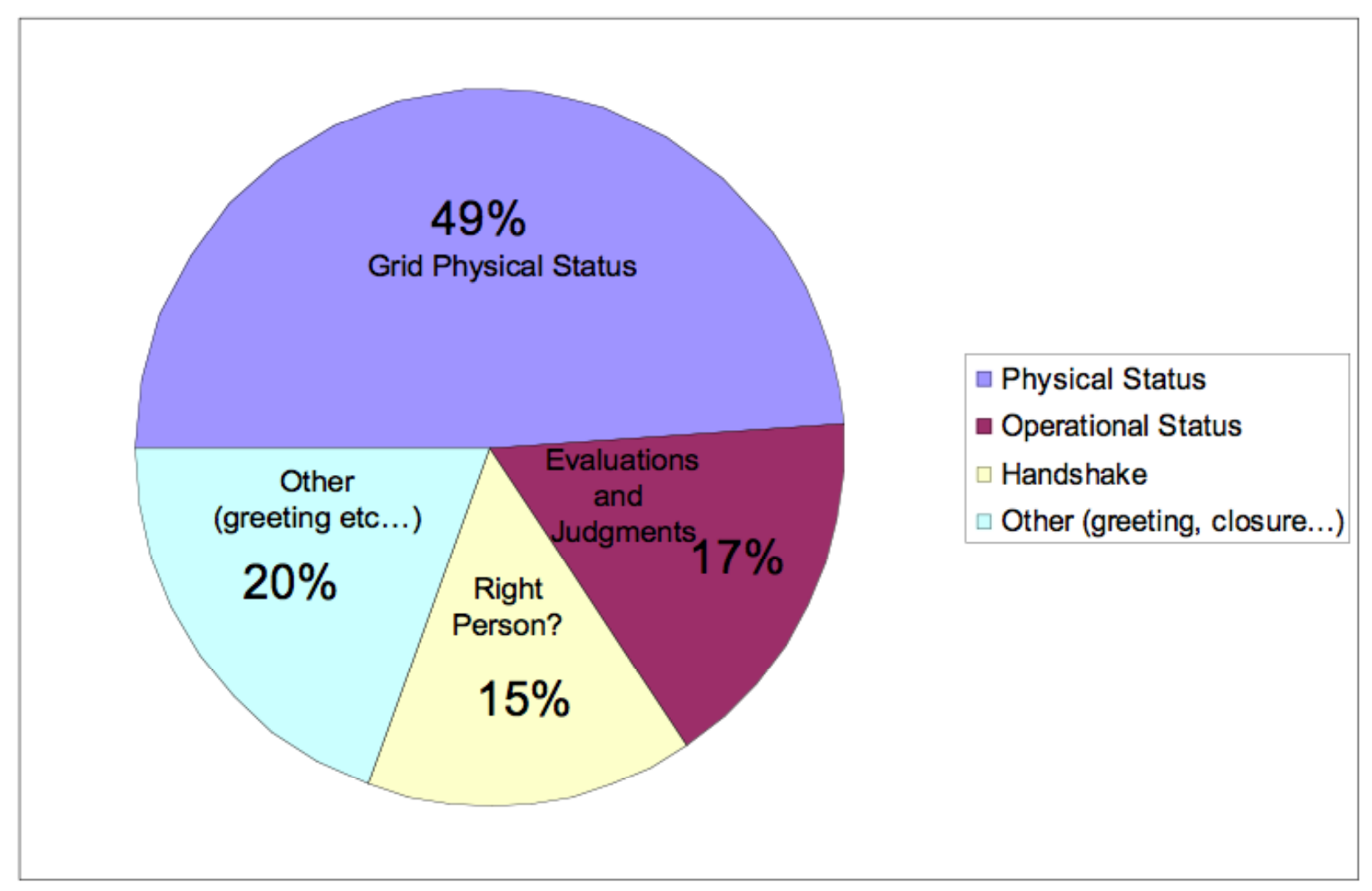

Figure 5. Relative Proportions of Information Exchanges Regarding Physical Status, Operational Status, Handshake, or Other

\subsubsection{Results}

The tabularized data are illustrated in the Figure 6. The keywords and patterns of information exchange were distilled from the detailed breakdown. A summary of key concepts is provided in Section 4.4.

In examining the transcripts, we sorted the information into relevant groupings or topics. What emerged from this sorting process were the following SA topics: emergency versus normal conditions, sharing of information, status of neighboring areas, corroboration of information, joint decision making, coordination of activities, and seeking information as "clues." Examples of discussion points in each of these categories are shown in Table 4. 


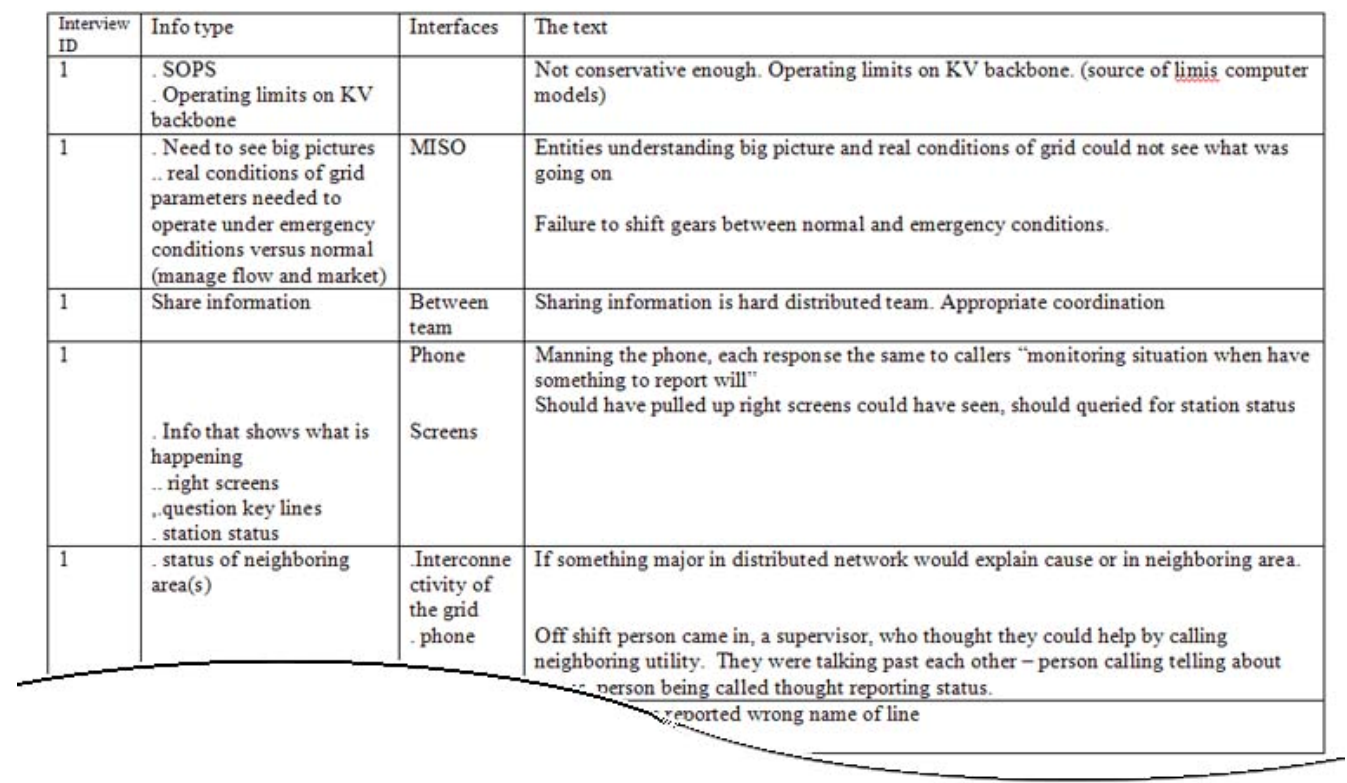

Figure 6. Example of Blackout Interview Analysis Information Breakdown

Table 4. Summary of Blackout Interview SA Concepts and Patterns

\begin{tabular}{|c|c|}
\hline Topics & Examples \\
\hline $\begin{array}{l}\text { Emergency versus Normal } \\
\text { Conditions }\end{array}$ & $\begin{array}{l}\text { - Scaling of procedures depending on conditions } \\
\text { - Responding to exponential increase in communications in } \\
\text { abnormal situations }\end{array}$ \\
\hline $\begin{array}{l}\text { Sharing of Information, Shared } \\
\text { Understanding }\end{array}$ & $\begin{array}{l}\text { - } \text { - } \text { Between distributed teams } \\
\text { - Common pouints of reference } \\
\text { - Common language (common understanding of connotations) } \\
\text { - } \quad \text { Level of precision/detail in exchange of information } \\
\text { - } \text { Familiarity of each other/region/group } \\
\text { - Culture of communication, team environment }\end{array}$ \\
\hline Status of Neighboring Areas & $\begin{array}{l}\text { - Feeling of "driving blind" or "driving with partial blinders on } \\
\text { - Incomplete topology } \\
\text { - Visibility of system outside one's own area, the 'space around a utility' }\end{array}$ \\
\hline $\begin{array}{l}\text { Corroboration/Verification of } \\
\text { Information }\end{array}$ & $\begin{array}{ll}\text { - } & \text { Human error } \\
\text { - } & \text { Timeliness of information } \\
\text { - } & \text { Measured versus estimated values } \\
\text { - } & \text { Incomplete information and sparseness of data points } \\
\text { - } & \text { Changing conditions } \rightarrow \text { changing degrees of validity } \\
\end{array}$ \\
\hline Joint Decision Making & $\begin{array}{l}\text { - Judging significance of events } \\
\text { - } \quad \text { Authority to make decisions (procedural, power, regulatory, expertise) }\end{array}$ \\
\hline Coordination Activity & $\begin{array}{l}\text { - Requests to inform others of action } \\
\text { - Establishing time to start action } \\
\text { - Request for specific action of an operator to occur at a specific time and } \\
\text { - } \text { to bring the system to a specific value } \\
\text { - Informing of activity completion } \\
\end{array}$ \\
\hline Information as 'clues' & $\begin{array}{l}\text { - } \text { Validation or correction of assumptions } \\
\text { - Recognition of missing info } \\
\text { - } \quad \text { Trends/patterns revealing outliers } \\
\text { - } \text { Patterns revealing signs of system weakness or stress, health of } \\
\text { - Intelligent alarming } \\
\text { - Localizing a problem }\end{array}$ \\
\hline
\end{tabular}




\title{
4.3 Informal Interviews
}

We conducted four interviews with grid operators and regional coordinators on situation awareness and information needs. We analyzed summaries of discussions about situation awareness between 14 operators and 12 trainers from the Eastern Interconnection.

\subsubsection{Method}

We developed an interview questionnaire and context-defining material to support the interview discussions and note-taking. The interview form and preparatory material set the context by defining the concepts of inside/outside an area of responsibility and a zone of 'normal' operations versus rarer or more serious operating conditions. The interview form and supporting material also served as a guide for interviewers to stimulate discussion and questions about situation awareness in different operating circumstances, with a focus on information needs outside of one's area of responsibility. The interview material was used to gather feedback regarding explicit and implicit current mechanisms that contribute to situation awareness and regarding additional information or mechanisms which could improve situation awareness outside of one's area of expertise.

\subsubsection{Results}

The informal interviews confirmed the results of the blackout phone transcript analysis and the patterns identified in the blackout interviews with experts and provided clarification on technical points that were identified. A number of specific ideas for ways of conducting experiments to test $\mathrm{SA}$ were also revealed through the informal interviews.

A summary of key concepts is provided in Section 4.4.

\subsection{Key Concepts and Patterns from Analyses of Transcripts and Interviews}

\author{
In an ideal world with universal access to complete ICCP data \\ across all regional control areas, operators would still feel the \\ need to call each other and exchange information on the \\ status of operations affecting the power grid.
}

A synthesis of findings and key concepts revealed in the analysis of transcripts and interviews is summarized below.

\section{Inadequate Communication/Information Sharing is Pervasive}

It is clear from the 2003 Blackout report that the failure to adequately communicate and share critical status information is not an isolated problem that happened during the afternoon of the blackout, but rather that it is a pervasive problem that clearly represents a systemic and chronic issue that must be corrected. It occurred throughout the day of August 14, 2003, contributing to lack of SA on all sorts of problems that were not related directly to the events of the blackout; and it occurred in the late afternoon of August 14 during the recovery period, hampering efforts for the various "actors" to gain situation awareness and effectively carry out their duties. Thus, the lack of a capability to share status information hampers performance of operators/dispatchers and coordinators in virtually all of their activities. One reason why operators/coordinators in different regions do not share information is that different companies use different software; the IT environments are not compatible or "interoperable" to use military terminology, so that 
passing of sensor data and status information (seemingly not a difficult proposition) is not done at this time. Only when ownership issues are resolved and an integrated/interoperable environment is supported across the grid will it be possible to share such data. Even when this (huge) integration problem is overcome, there is still the critical human factors problem (requirement) to identify exactly what information is needed to share, and how to represent that information.

\section{Information is available, but not used}

Many tools and mechanisms exist for operators to build awareness of the physical grid system, yet the transcripts reveal that they still need to call and exchange information with operators of neighboring areas to improve this SA. The specific types of information that they request are quite predictable and, in most cases, cover information that is available to both operators and reliability coordinators through readily available displays or other data sources. So, if this information is already available through grid monitoring tools, why does one operator call another to get such information? The blackout interviews reveal a number of reasons for operators to seek corroboration or verification of information relevant to the grid status in areas outside their area, for example:

- Human error or machine error is possible

- 'Data' reflecting the status of the power grid may be seen as coming in many flavors, for example:

o Measured versus derived values

o Sparse to dense data points

o 'Real-time' to historical

o Based on planned studies versus based on calculations representing recent contingencies, etc.

o Stemming from one data stream versus another

o Manipulated by one software tool versus another.

- One control area may have limited access to information from outside control areas

o One area may or may not have ICCP data on a given outside area, and that data may be more or less timely or extensive

o Some areas have substations that are fully automated with extensive SCADA data, others do not

o Some areas have automated electronic tagging and electronic tagging, others do not

o The specific types of Energy Management Systems and corresponding grid operation software installed in control rooms may vary

o The specific arrays of software engines used to extrapolate and tighten data points may differ from one area to another.

\section{Shared Knowledge is Required on Operations/Actions as Well as Physical Status}

In an ideal technologically and organizationally perfect world, every control room and every reliability coordinator may have access to complete ICCP data across all regional control areas and yet, there would still be reason for the operators to call each other to gain and improve their SA of power grid operations. Analysis of both the blackout transcripts and interviews with experts reveal the importance of exchanging information about the status of operations affecting the power grid — what decisions are being considered, what decisions have been made and where in context of location in the grid, what actions have been taken, which actions are about to be taken and where, what options are available, what other factors need to be considered. While operators and reliability coordinators seek to improve their SA of the general status of neighboring areas, it is 
not just the physical status of grid components that is needed to refine that SA. Operator and RC situation awareness of neighboring areas includes a general understanding of the status of operations in areas outside their area. Because power grid status is in constant flux, aspects which affect that flux are of vital importance, including trends in physical grid status and on-going actions and mindsets of grid operators.

Figure 7 summarizes the concept of increasing SA outside of a given operator's control area. In the most limited sense, an operator establishes SA based on a more or less complete and more or less accurate mental picture of the physical status in his/her control area. With increasing information and knowledge about other control areas, the operator's mental picture expands to encompass a partial picture of physical status in adjoining areas, which affect the SA of one's own control area. Finally, to have shared SA for optimal 'sensemaking', an operator also needs to be aware of the operational situation in outside control areas: what are other operators thinking and doing and planning to do, what actions are underway, how is the status evolving or expected to evolve.

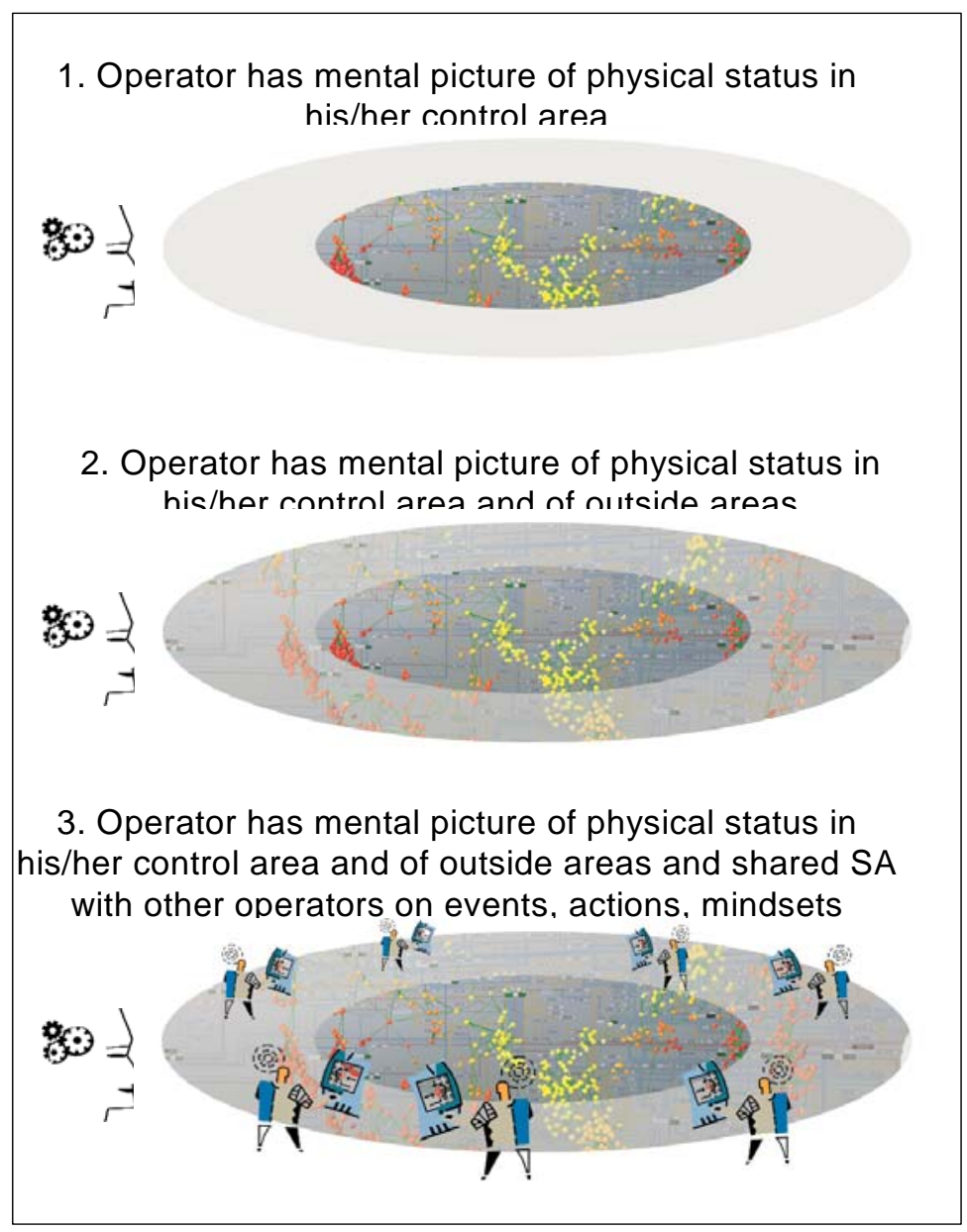

Figure 7. Increasing SA Outside of One's Control Area Toward Shared SA 


\title{
5. Discussion
}

\author{
It is not sufficient that the new information needs of the \\ operators be examined solely from an individual viewpoint: It \\ is critical that an understanding be gained from the perspec- \\ tive of a shared view. Notions of "normal" and "abnormal" \\ operational conditions need to be revisited within a more \\ dynamic, continuous context that has implications for the \\ way we define experiments and assess tools aimed to improve \\ situation awareness.
}

\subsection{Summary of Findings from Review of Literature and Human Factors Practice}

Consider once again the taxonomy that was introduced in Section 1 (a portion is reproduced in Figure 8).

- Data. At this level of R\&D application or technology insertion, technology has vastly increased the reliability and safety of the grid. New measuring devices and sensors, more powerful and refined communication systems, advanced power electronic devices, and new control and protection ideas have resulted in increased automation and increased data available at the distribution, transmission, and generation levels. Despite these advances in technology, the operator is overwhelmed with information and cannot effectively assimilate the data effectively to take necessary actions to maintain the stability of the grid. Examples of research/technology addressing the Data Level include SCADA data and phasor data. Power grid SA is affected by the reliability, completeness, and vastness of data, This level can be improved through organizational actions (e.g., increasing access to ICCP data) and through tools and visualizations (e.g., systems which provide an indication of 'confidence' level of specific data).

- Data Compilation \& Processing. This level focuses on compilation or processing strategies to speed up the processing of data. This includes technologies that organize data in a form that enables number-crunching using efficient algorithms and/or data-intensive computing approaches such as parallel computing, cell processor, etc. Ongoing research at PNNL focuses on computational assets and methods to speed up the processes of generating data/information that comprises the current status information used today. But simply passing that information to other operators/RCs is not the answer.

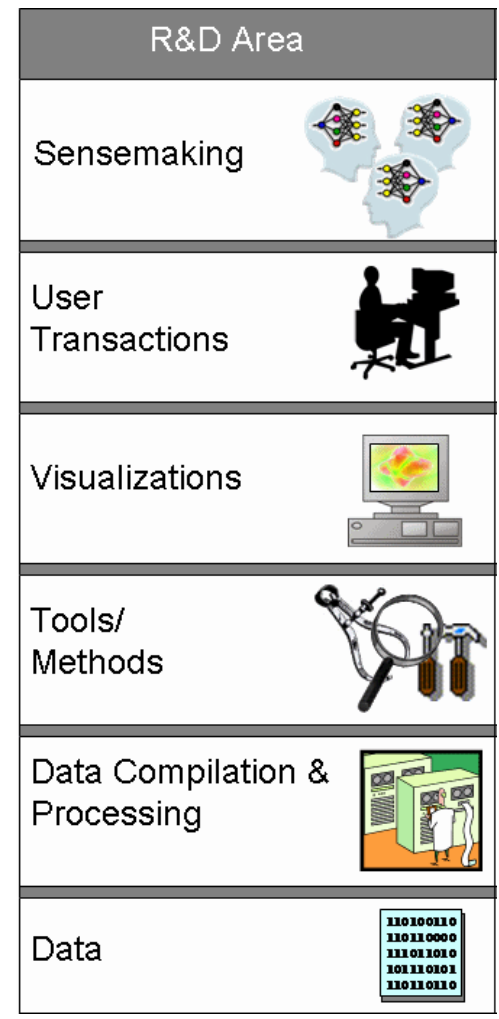

Figure 8. Taxonomy of $R \& D$ for Power Grid HF/SA 
- Tools/Methods. This level includes approaches to provide new methods and tools, such as modeling/simulation software, to enhance decision making. For example, tools and methods are provided to facilitate the process of determining market value from planning, purchasing and selling energy. Generally, these methods and tools leave it to the operators to integrate diverse information in achieving a broader perspective, i.e., SA about information within and outside of their areas of responsibility so they can make better decisions to keep the grid stable. There are many examples of such tools: State Estimator, Contingency Analysis., load shedding schemes, Power World... PNNL is involved in ongoing research on tools such as the 'Phasor State Estimator' and the 'Mode Meter' (showing oscillation damping trends). SA experiments can be devised to study the relative gains provided by new tools and methods such as these.

- Visualizations. The visualization technology development area focuses on providing users with a portal or view of the data. The results of this effort are coupled with the algorithms, models, and tools to assist the operator in making sense of the data. Rather than provide the operator with the data as numbers, graphical representations are displayed. Much human factors effort is devoted to designing these views to establish views or visualizations that are most appropriate to support operational decision making. These visualizations take many forms from simple alarm lists to color representations such as schematics of the transmission lines of the grid, pie charts, and transmission directional flows overlaid over a geographical map. While these visualizations have greatly enhanced the operators' ability to view more information at once, often the information represents a single technical aspect of the system and the operator must integrate the data from multiple visualization sources to synthesize and make sense of the information (e.g., dashboard visualization; design and empirical research by Overbye). There have been attempts to convey high level/topological status information (e.g., in Areva's latest software), but the determination of what exactly to display/share and how to represent it remain research questions.

- User Transactions. This includes the traditional human factors R\&D on user-computer interaction, display design, and factors affecting SA. Since deregulation, complete information is seldom available to operators, yet they are responsible for maintaining the health and stability of a specific geographical area in the context of an interconnected grid. Thus they must deal with increased technical complexity and missing information. As we have described in the literature review, much traditional human factors research puts a great deal of emphasis on what the operator knows and what the operator doesn't know-focusing on the information elements and the interaction with those elements for a particular visualization. For example, Endsley and her team have addressed the SA and other human factors issues using task-based approaches and failure mode analysis to address what people should have noticed (the past) and why they did not in the context of what is available on current systems and operational practices. While insight is gained about the operators' new needs from a failure-mode perspective, it is also important to address new needs in a broader context of normal operations that are fluid, where the system moves between contingency conditions and normal operations. As we have observed, research must address normal operations states that include the situation in which the system is running in a contingency state that is not necessarily bad. 
- Sensemaking. Notions of sensemaking and shared knowledge have been described by a few researchers; this level of R\&D is embraced in the current LDRD project. Our findings suggest that an important factor in this sensemaking perspective of SA is that the decision makers need to be concerned with and aware of particular events and actions that are unfolding inside and outside their geographic areas of responsibility so they will be able to maintain the health and stability within their area of responsibility. The solutions that have been studied to date, reflecting Levels 1 through 5 in our taxonomy, are not designed with these new sensemaking/ shared knowledge needs in mind to systematically incorporate these concepts (and their implications for displays, visualizations, communications/information sharing, etc.) into daily practices and training.

In summary, it is not sufficient that the new information needs of the operators be examined solely from an individual's viewpoint: it is critical that an understanding be gained from the perspective of a shared view, since the events that unfold and associated sensemaking requirements do not occur in vacuum but are intimately involved, temporally and spatially, with events and conditions outside of an individual's responsibility and awareness (access). Resolution of a problem requires coordination among multiple parties whose role is to maintain the health and stability of the grid. This requires more information sharing and shared views of the data.

\subsection{Implications}

\section{Need to redefine "Normal Operations"}

"Normal operations" is a fluid state of events. Combinations of parameters are constantly moving inside and outside the norm of operations. The concepts surrounding 'normal' and 'abnormal' operating conditions are illustrated in Figure 9. The four quadrants serve to illustrate the vagueness of the concept of 'normal' operations, and the fact that it is very common for operators to be confronted with situations which may have serious consequences or situations which occur rarely and thus may be hard to identify or understand.

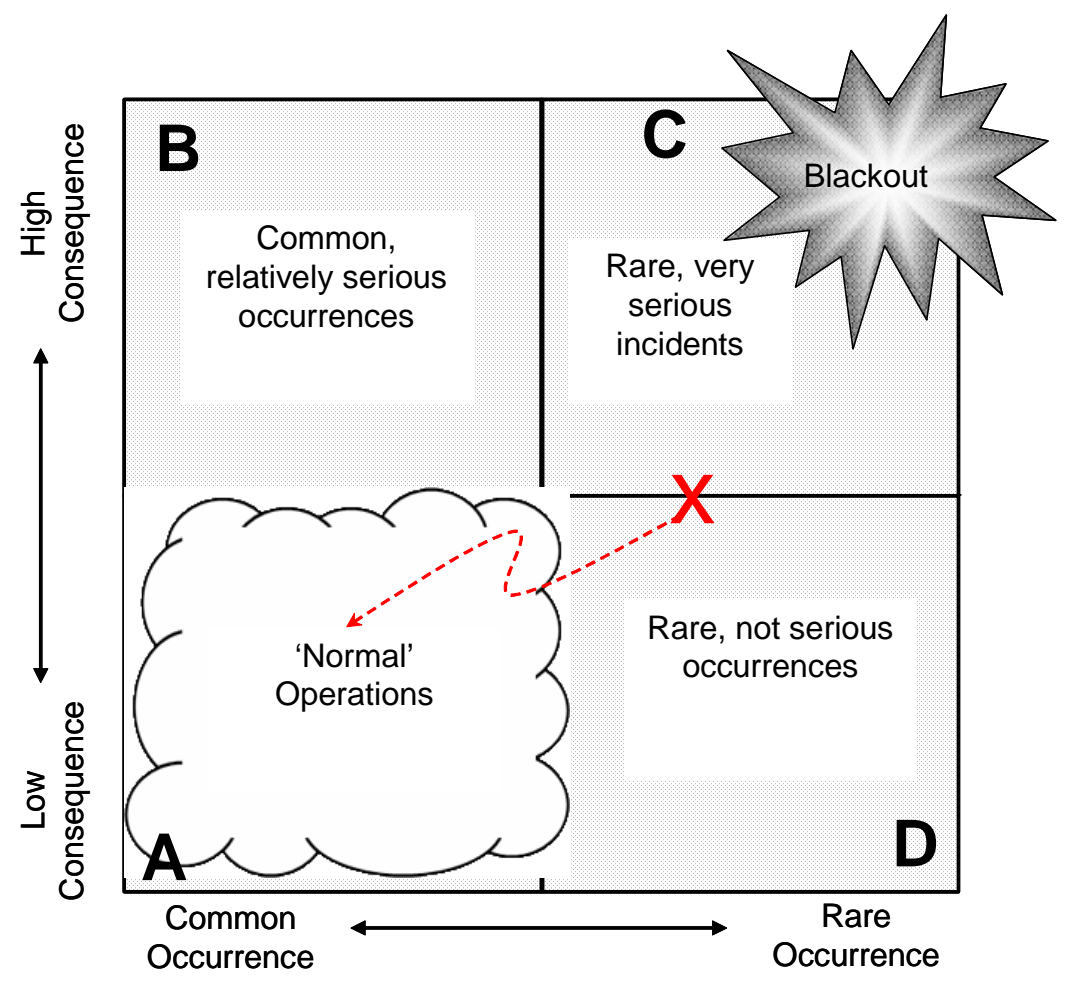

Figure 9. Situations of Interest in Power Grid Operations 
Interviews and analysis of the August 14th blackout revealed a pattern where operators and reliability coordinators considered the movement of parameters beyond the traditional limits of normal operations as normal because the condition was categorized as a common relatively serious occurrence. Traditional studies have characterized this condition as abnormal and studied as such where they are actually investigating what the operator needed (past) as a static reference. Instead, what is needed is establishing the PRESENT status in context of a dynamic or fluid point of reference. This new perspective was identified by the reoccurring pattern of the gaps of information flagged by the observables of operators and reliability coordinators requesting the needed information or reporting in the interviews the information they were seeking and needed to be shared.

\section{Notion of sensemaking and shared knowledge}

Our analysis identified a need for shared information to accomplish:

- Normal status checking/coordination

- Reporting discovered serious problems and discussion of impact of actions to resolve problems

- Establishing status to diagnose problems

- Specific action coordination (not serious action)

- Black start planning/coordination

- Restoration

- Specific requests inquiring about serious problems.

While the above items identify the functions that would be served by the shared information they do not address WHAT the information should be and HOW it should be provided.

Drilling down to what enables theses functions, analysis indicated that the most important information that operators and RCs need to share to perform the above functions is information about:

- Physical system status

o Trips

O Overloads (precursors to trips)

o Violations (going off normal conditions; also precursors to trips)

o Unscheduled events

o Areas with no power

- Operational system status

o Decisions and actions

o Events (scheduled or expected).

\section{Implications about the type of research that is needed}

We conclude that the findings and perspectives presented in this report argue that a promising direction for future research on human factors/situation awareness in power grid operations is to focus on further defining factors and user interaction/tool requirements that address issues of sensemaking and shared knowledge. This means that research is needed that transcends the more traditional human factors/ visualization studies centered on transactions between the user and the computer. Possible research studies following this line of thought are briefly described in the next section. 


\subsection{Path Forward}

The PNNL EIOC is uniquely positioned to support research on issues affecting SA and their implications for tool development, as well as a test bed for evaluating the usefulness and effectiveness of tools or possible interaction design and visualization solutions. We envision both highly focused experiments investigating specific design issues (i.e., questions addressing transactional user interface design and visualization concepts) as well as broader, high-level issues that address wide-area indicators and factors affecting shared SA.

\subsubsection{Research Methodology}

The basic notion is to utilize the resources within the EIOC to run a series of experiments investigating one or more SA factors (specific factors/variables are described below). To accomplish this, a collection of brief scenarios must be created and EIOC simulation resources must be used to implement them within simulated "exercises."

To serve the methodological needs of the proposed experiments, various control conditions are needed. For example, assessing the effectiveness of a particular visualization or concept for information sharing requires a comparison of performance with and without the enhancement. Therefore a baseline condition should be run without the experimental manipulation in each study. At a minimum, the experimental manipulation would include the incorporation of the new method/visualization into the paradigm. Additional experimental conditions that would be of interest include running more levels of experimental factors, such as by varying the workload/stress of the problem. This would require additional specification of factors underlying workload or task difficulty. One possible way of operationally manipulating workload, for example, would be the incorporation of a simultaneous/secondary task such as phone calls. The amount of phone calls that need to be fielded could be varied to manipulate this aspect of workload. Other ways to vary workload or difficulty would involve creation of simulated scenarios that vary certain difficulty-related parameters such as pace of events, number of events, severity of events, number of operators/decision makers required for coordination. Regarding the latter variable, some variations on experiments may require the use of teams of users, such as system dispatcher, RAS, supervisor at separate stations. This would be useful in studies of shared knowledge and coordination.

Other factors that may be manipulated or controlled include:

- various conditions of the grid: normal, contingency normal (moving the system back from the contingency quadrant into normal)

- status of system (normal, contingency, grid restoration, other)

- loads/limits

- environmental conditions (weather flow, lightning)

- consumer behavior

- disturbance indicators (frequency of calls, number of faults, ratio of scheduled versus unscheduled actions)

- extent of information sharing (local view versus local plus outside views).

\subsubsection{Possible Variables to Manipulate}

Following are examples of ideas for empirical studies that may be run within the PNNL EIOC laboratory by implementing scenarios and varying one or more factors. Examples of variations in experimental and control conditions are suggested. 
1) Examine SA-type benefits of tools that exist technically but are not necessarily implemented or in widespread use

a) Automated mapboard and electronic tagging of one's own control area

b) Electronic tagging shared with neighboring control areas

c) Shared fault indication across control areas

d) Shared information on system/topology changes across organizational boundaries (e.g., switch A out for repair, replaced by parallel switch B).

2) Examine SA-type benefits of new tools (more timely information, more 'accurate' or 'reliable' information, finer mesh of information)

a) Phasor data visualizations

b) Other new, wide-area, big picture indicator visual integrating geographical and status information, for example the real time dispatcher monitoring system (RTDMS, by the Electric power group).

3) Compare visualizations

a) Current displays (e.g., tabular), local view

b) New display concepts, integrated view (e.g., PI diagrams providing visualization of high level transmission flows, or new displays from e-terra vision by Areva)

c) Enhanced version that incorporates sharing of information from outside area. In such a study, one type of manipulation would involve the implementation of the shared view of the situation.

4) Study concept of confidence in information. How confident is operator $X$ in the information he/she sees, how does that level of confidence affect his/her SA, how can one increase that confidence?

a) Missing information and/or Misinformation

i) Within one's own system

ii) Outside one's area

b) Uncertain information, timeliness of information

i) Within one's own system

ii) Outside one's area

c) Get at example from transcripts where operator A calls operator B to say "I'm seeing XYZ on line $\mathrm{M}$, what are you seeing?”

5) Study concepts of 'shared understanding' and 'shared awareness'

a) Record picture of who is aware of what

b) Test logging and shared logging of 'notes' about system status, events, and operator understandings.

6) Study non-scalability of procedures/tools, HF role with increasingly critical conditions. Focus on communications, increasing need, increasing calls

a) Relationship to SA 
b) Effects on $\mathrm{SA}$

c) SA tools that can help.

\subsubsection{Performance Measures}

Any experimental study needs to have well-defined performance measures. The following is a nonexhaustive list of possible measures and considerations that must be addressed in planning and setting up simulation-based experiments within the EIOC.

- Record time needed for operator to take action X. Experiment must have obvious, systematic path to event or action $\mathrm{X}$, requiring obvious, clear action.

- Assess quality of decision/action taken.

- Question/Quiz participants about system conditions at outset of exercise and after. Experiment must provide example of condition that clearly changes.

- Have participants log specific things during simulation (e.g., time event, question, action).

- Log and analyze all communications (between operators inside EIOC; with operators at other locations).

- Measure awareness about key concepts:

o Time awareness (when do limits start, how much time do you have to resolve...)

o Line outage awareness

o Component outage awareness

o Neighboring system outage awareness

o Reactive power conditions awareness

o Voltage sag awareness

o Frequency excursion/trend awareness

o Expected action awareness.

\subsubsection{Specific EIOC HFISA experiments}

Using the broad array of power grid operations technologies currently under development at PNNL, along with the advantages of the EIOC as a testing 'laboratory' to simulate control room operations, a number of human factors experiments can be imagined. As a starting point, a series of short simulation segments must be developed to support experiments under control conditions (for example, using baseline technology) and test conditions (for example, adding a new tool or new method to support shared SA), and the corresponding system model and supporting tools must be fully configured and operational. Building on this solid basis of simulation runs, year two of this research proposes running one or more focused tests. The tests will be primarily designed along two lines, with possible variations that are not discussed here.

First, an experimental scenario will aim to test basic, more traditional aspects of SA and ergonomics. This type of study will aim to answer questions such as, "Which visualization option, A or B, is more effective?", or "Which tool is better under these fixed conditions?", or "Does the addition of this tool increase SA about a specific factor?" One possibility will be to study the effect on individual SA of a 'Mode Meter' tool (developed by PNNL; see Figure 10) that provides an indication of trends in system status across a wide area. 


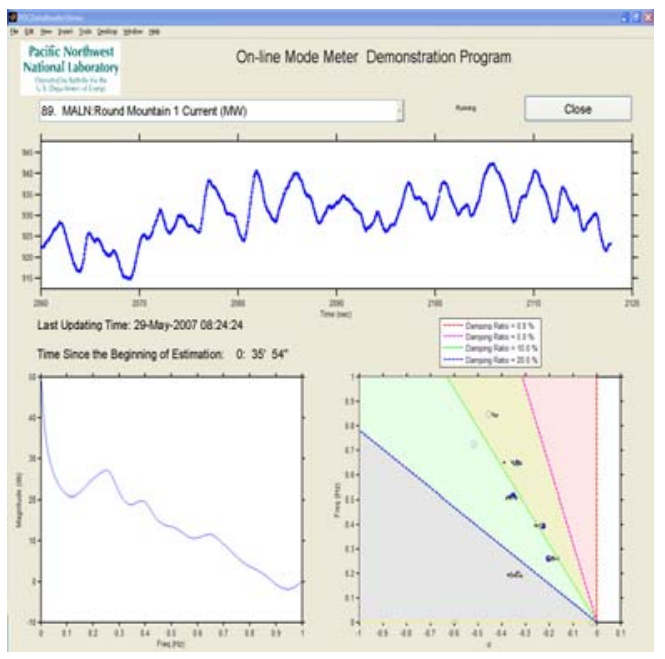

Figure 10. Example of the 'Mode Meter' Visualization of Oscillation Damping

Second, an experimental scenario will aim to study shared SA and the impact of various tools or information sharing mechanisms on shared SA. To study the effect on SA of sharing common 'views' of system status, this study will involve coordination between operators in the EIOC and in a separate location (e.g., representing an RC). For example, in the control situation, operators will be at individual operations posts using different, traditional displays. In the first test situation, EIOC operators and the RC will have the capacity of 'sharing' a traditional display as they speak. In a second test situation, EIOC operators and the RC will 'share' a new visualization providing an overview of system status (this may be a tool such as the 'Mode Meter' or the 'RTDMS', or may be a new EIOC development or Pi diagram). 


\section{Conclusions and Recommendations}

With increasing complexity and interconnectivity of the grid, the scope and complexity of situation awareness have grown. While reliability coordinators and control area operators have much information available to them, there is an explicit need to share information that enables them to make sense of what is happening and gain situation awareness for the timely safe operation of the grid. Typically they are seeking this contextual information to make decisions or take actions. Simply, if the information is not provided, they may not be able to perform the appropriate action or decision.

This study conducted interviews on SA in power grid operations and reviewed scientific research, systems/tools, and historical summaries and transcripts of abnormal conditions and outages. To better follow developments in the field, we described a taxonomy of R\&D on tools and methods in the field of human factors/SA for grid operations. We concluded that new paradigms are needed to guide research and tool development aimed to enhance and improve operations. We advocated a new perspective on SA in terms of sensemaking, where the focus of the investigation is to understand why the decision maker(s) experienced the situation the way they did, or why what they saw made sense to them at the time. This perspective is distinct from much of the traditional research in the field. We recognized an over-arching need to focus SA research on issues surrounding the concept of shared knowledge; e.g., awareness of what is happening in adjacent areas as well as one's own area of responsibility.

Major findings were:

- Inadequate communication/information sharing is a pervasive problem that clearly represents a systemic and chronic issue that must be corrected.

- Information is available, but not always used: operators still need to call and exchange information with neighboring areas to improve SA. Much of the information is available to both operators and reliability coordinators in displays or other data sources. This indicates that changes are needed in current displays/tools to increase the availability and utility of information.

- Information about the status of operations affecting the power grid-what decisions are being considered, what decisions have been made and where in context of location in the grid, what actions have been taken, which actions are about to be taken and where, what options are available, what other factors need to be considered—should be shared along with physical status information.

- There is a need to redefine "Normal Operations." Combinations of parameters are constantly moving inside and outside the norm of operations. Interviews and analysis of the August 14 blackout found a pattern where operators and reliability coordinators considered the movement of parameters beyond the traditional limits of normal operations as normal because the condition was categorized as a common relatively serious occurrence. Therefore there is a need to establish the PRESENT status in context of a dynamic or fluid point of reference.

- A promising direction for future research on human factors/ situation awareness in power grid operations is to focus on further defining factors and user interaction/tool requirements that address issues of sensemaking and shared knowledge. This means that research is needed that transcends the more traditional human factors/visualization studies centered on transactions between the user and the computer. 
The PNNL Electricity Infrastructure Operations Center (EIOC) is uniquely positioned as a test bed for evaluating the utility and effectiveness of tools or possible interaction design and visualization solutions and to examine issues affecting SA and their implications for tool development. We envision both highly focused experiments investigating specific design issues (i.e., questions addressing transactional user interface design and visualization concepts) as well as broader, high-level issues that address wide-area indicators and factors affecting SA.

Research studies following this line of thought may be designed and conducted within the EIOC to examine the effectiveness of alternative visualizations or concepts for information sharing by varying experimental factors such as workload or task difficulty, individual or team performance, and various other conditions. 


\section{References}

Banbury, S., and Tremblay, S. (2004). A cognitive approach to situation awareness: Theory and application. Burlington, VT: Ashgate Publishing Company.

Chipman, S.F., Schraagen, J.M., and Shalin, V.L. (2000). Introduction to Cognitive Task. Analysis. In Schraagen, J.M., Chipman, S.F., and Shalin, V.L. (Eds). Cognitive Task Analysis. Mahawah, NJ: Lawrence Earlbaum Associates, pp. 3 - 23.

Dekker, S., and Lutzhoft, M. (2004). Correspondence, cognition and sensemaking: A radical empiricist view of situation awareness. In S. Banbury and S. Tremblay (Eds.), A cognitive approach to situation awareness: Theory and application. Burlington, VT: Ashgate Publishing Company, pp. 22-41.

Endsley, M.R. (1988). Design and evaluation for situation awareness enhancement. Paper presented at the Human Factors Society 32nd Annual Meeting, Santa Monica, CA.

Endsley, M.R. (1995). Toward a theory of situation awareness in dynamic systems. Human Factors, 37(1), 32-64.

Endsley, M.R., Bolte, B., and Jones, D.G. (2004). Designing for Situation Awareness. London, England: Taylor \& Francis.

Flach, J., Mulder, M., and van Paasen, M. M. (2004). The concept of the situation in psychology. In S. Banbury and S. Tremblay (Eds.), A cognitive approach to situation awareness: Theory and application. Burlington, VT: Ashgate Publishing Company, pp. 42-60.

Gordon, S.E., and Gill, R.T. (1997). Cognitive task analysis. In Zsombok, C. and Klein, G. (Eds). Naturalistic Decision Making. Mahwah, NJ: Erlbaum.

Greitzer, F. L., Hershman, R. L., \& Kaiwi, J. (1985) Intelligent interfaces for $\mathrm{C}^{2}$ operability. In Proceedings of the IEEE International Conference on Systems, Man, and Cybernetics. November 1985.

Klein, G., Moon, B. and Hoffman, R.F. (2006). Making sense of sensemaking I: alternative perspectives. IEEE Intelligent Systems, 21(4), 70-73.

Miller, G. A. (1956). The magical number seven, plus or minus two: Some limits on our capacity to process information. Psychological Review, 63, 81-96.

NERC. (2004). A Review of System Operations Leading up to the Blackout of August 14, 2003. NERC Report, January 12, 2004.

Overbye, T. J., Meliopoulos, A.P., Wiegmann, D.A., \& Cokkinides, G.J. (2005) Visualization of Power Systems and Components: Final Report. University of Illinois at Urbana-Champaign. Power Systems Engineering Research Center (PSERC) Publication 05-065.

Rousseau, R., Tremblay, S., \& Breton, R. (2004) Defining and modeling situation awareness : A critical review. In S. Banbury \& S. Tremblay (Eds.), A cognitive approach to situation awareness: theory and application. Burlington, VT: Ashgate Publishing Ltd,. pp. 3-21.

Weick, K.E. (1995). Sensemaking in organizations. Thousand Oaks, CA: Sage Publications. 